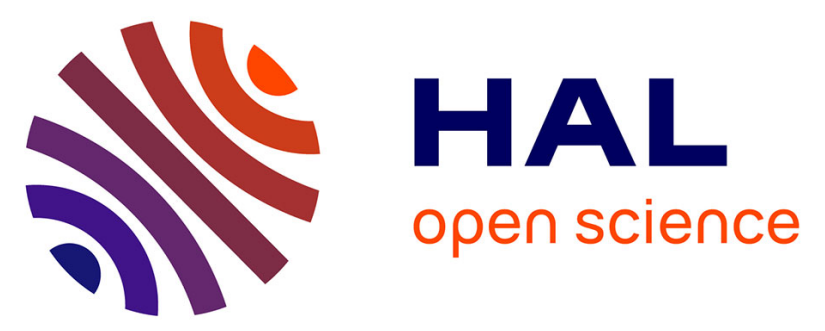

\title{
Liquid/Liquid Extraction Kinetics of Eu(III) and Am(III) by Extractants Designed for the Industrial Reprocessing of Nuclear Wastes
}

T. H. Vu, Jean-Pierre Simonin, A. Rollet, R. J M Egberink, W. Verboom, M. C Gullo, A. Casnati

\section{To cite this version:}

T. H. Vu, Jean-Pierre Simonin, A. Rollet, R. J M Egberink, W. Verboom, et al.. Liquid/Liquid Extraction Kinetics of Eu(III) and Am(III) by Extractants Designed for the Industrial Reprocessing of Nuclear Wastes. Industrial and engineering chemistry research, 2020, 59 (30), pp.13477-13490. 10.1021/acs.iecr.0c02401 . hal-02924724

\section{HAL Id: hal-02924724 \\ https://hal.sorbonne-universite.fr/hal-02924724}

Submitted on 28 Aug 2020

HAL is a multi-disciplinary open access archive for the deposit and dissemination of scientific research documents, whether they are published or not. The documents may come from teaching and research institutions in France or abroad, or from public or private research centers.
L'archive ouverte pluridisciplinaire HAL, est destinée au dépôt et à la diffusion de documents scientifiques de niveau recherche, publiés ou non, émanant des établissements d'enseignement et de recherche français ou étrangers, des laboratoires publics ou privés. 


\title{
Liquid/liquid extraction kinetics of $\mathrm{Eu}(\mathrm{III})$ and
}

\section{Am(III) by extractants designed for the industrial reprocessing of nuclear wastes}

\author{
T.H. Vu, ${ }^{\dagger}$ Jean-Pierre Simonin, ${ }^{* \dagger} \dagger$ A.L. Rollet, ${ }^{\dagger}$ R.J.M. Egberink, ${ }^{\ddagger}$ W. Verboom,${ }^{\ddagger}$ \\ M.C. Gullo, and A. Casnati \\ $\dagger$ †NRS, Laboratoire PHENIX, Campus P.M. Curie, Sorbonne Universités, F-75005, Paris, \\ France \\ $\ddagger$ Laboratory of Molecular Nanofabrication, University of Twente, Enschede, Holland \\ \D.to di Scienze Chimiche, della Vita e della Sostenibilità Ambientale, Università di \\ Parma, Parma, Italy \\ E-mail: jpsimonin@gmail.com
}

\begin{abstract}
Results about the kinetics of extraction of $\mathrm{Eu}(\mathrm{III})$ and $\mathrm{Am}(\mathrm{III})$ by extractants designed for the industrial reprocessing of nuclear wastes are reported. They were obtained using the rotating membrane cell technique (RMC). Extraction and stripping kinetic rate constants were determined for various compositions of the aqueous and organic phases. The transfer was studied at liquid/liquid interfaces between an aqueous nitric acid solution and an organic solvent containing the diglycolamide extractant molecule TODGA, or a mixture of the bipyridine molecule $\mathrm{CyMe}_{4} \mathrm{BTBP}$ with TODGA (the latter being used as a phase-transfer catalyst), dissolved in an aliphatic diluent. In some experiments, an aqueous ligand (a sulfonated bis triazinyl pyridine, $\mathrm{SO}_{3}-\mathrm{Ph}-\mathrm{BTP}$,
\end{abstract}


or a PyTri-diol) was added to the aqueous phase as a stripping agent. The diffusion coefficients of $\mathrm{Eu}(\mathrm{III})$ and $\mathrm{Am}(\mathrm{III})$, that are key in the analysis of the kinetic data, were measured using the RMC and the closed capillary technique. Whenever possible, mechanisms are proposed to interpret the experimental results.

\section{Introduction}

The reprocessing of nuclear wastes resulting from spent nuclear fuel is a worldwide topic of utmost importance in the nuclear industry and for the society itself. Various processes, generally based on liquid/liquid (L/L) extraction stages, have been proposed with the aim of reducing the volume, heat and radiotoxicity of highly radioactive waste (plutonium and americium in particular) for their disposal in a geologic repository. ${ }^{1}$ These processes involve the separation of the most problematic radioactive elements in the wastes.

Various strategies have been developed worldwide for the reprocessing of used fuel. An overview of the main solvent extraction processes $^{2}$ (besides Europe) is presented in Table 1. References are indicated in the table that give more details on the policies of the countries in this domain.

Table 1: Main reprocessing strategies worldwide.

\begin{tabular}{llllcc}
\hline Country & Name & Extractant & Aim $^{a}$ & TRL $^{b}$ & Refs. $^{a}$ \\
\hline \multirow{2}{*}{ USA } & TRUEX & CMPO + TBP & Extract U, Pu, Am, Cm & $5-7$ & 3 \\
& TALSPEAK & D2EHPA & An/Ln separation & $4-5$ & \\
China & TRPO & Cyanex 923 & Extract Pu, Am, Cm & $4-5$ & $4-6$ \\
& Cyanex 301 & Cyanex 301 & Extract An & $4-5$ & \\
\multirow{2}{*}{ Japan } & SETFICS & CMPO + TBP & Extract An \& Ln & $3-4$ & 4 \\
& ARTIST & D2EHBA, TODGA & Recover U, TU & $2-3$ & \\
India & TRUEX & CMPO + TBP & Extract U, Pu, Am, Cm & $5-7$ & 4 \\
\hline
\end{tabular}

${ }^{a}$ Ln=lanthanide, An=actinide; ${ }^{b}$ Technology Readiness Level; ${ }^{c}$ Transuranic elements

In Europe this topic has been tackled with determination through the financing of successive European EURATOM projects since the early 90's: NEWPART, PARTNEW, EUROPART, ACSEPT, SACSESS, ${ }^{7}$ and now GENIORS (GEN IV Integrated Oxide fuels Re- 
cycling Strategies). ${ }^{8}$ The European approach was centered around the use of selective extractants and molecular diluents that would generate a minimal amount of secondary waste. A feature of this strategy is the use of chemicals that only comprise the $\mathrm{C}, \mathrm{H}, \mathrm{O}$, and $\mathrm{N}$ atoms (often referred to as the CHON principle $^{9}$ ), which makes them suitable for subsequent incineration.

Reference aqueous separation process routes have emerged from these in-depth studies. They are depicted in Figure 1. ${ }^{10,11}$

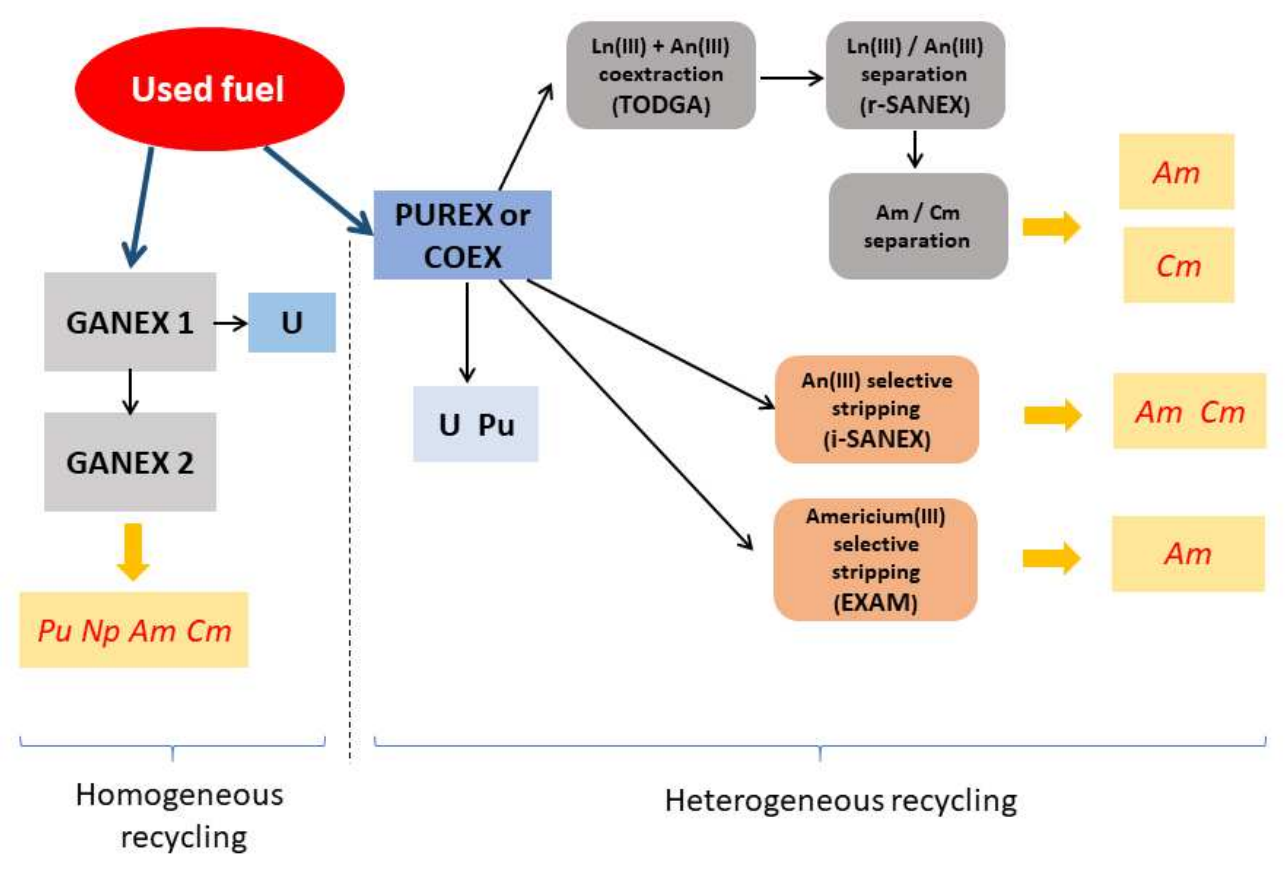

Figure 1: Main routes of the European partitioning process strategy envisaged for the recycling of actinides $(\mathrm{An})$ from used fuel $(\mathrm{Ln}=$ lanthanides $)$. EXAM $=$ Extraction of americium.

One route uses the GANEX (Grouped Actinide EXtraction) process ${ }^{12,13}$ in which uranium is separated from the waste in a first step, and then transuranic actinide elements are isolated ( $\mathrm{Np}, \mathrm{Pu}, \mathrm{Am}$, and $\mathrm{Cm})$ from all fission products.

In the other route, the PUREX (Plutonium, Uranium, Reduction, EXtraction) process, ${ }^{14}$ first implemented in the Manhattan project, is employed for the separation of uranium and 
plutonium from other fission products by using tributyl phosphate (TBP) as the extractant. The COEX process is a modified version of PUREX. Then the DIAMEX (DIAMide EXtraction) process developed at CEA (Commissariat à l'Energie Atomique) in France may be used. It consists of the co-extraction of trivalent minor actinides (MA's, mainly composed of americium(III) and curium(III)) and lanthanides (Ln's) from a PUREX raffinate by employing a malondiamide extractant. Although they constitute less than $0.1 \%$ of the initial spent fuel mass, the minor actinides (especially neptunium, americium, and curium) will be the main contributors to the radiotoxicity (and heat generation) after a three century storage of high-level radioactive liquid waste (obtained after the PUREX stage). In the mixture so obtained, MA's and Ln's may be separated by using the r-SANEX (Regular Separation of ActiNides by EXtraction) process. ${ }^{15}$ The separation of Ln's from MA's is required for the subsequent transmutation of MA's into short-lived or stable nuclides (which is the aim of the so-called "Partition and Transmutation" strategies ${ }^{16}$ ).

It has been proposed to replace the malondiamide molecule used in the DIAMEX and SANEX processes by a diglycolamide, which results from the insertion of an ether group between the two amide groups of the malondiamide. The reference molecule is the N,N,N',N'Tetra-n-Octyl-DiGlycolAmide (TODGA) that was first synthesized by a group from the Japan atomic Energy Agency. ${ }^{17}$

Variations of the original SANEX step have been proposed in order to reduce the number of stages following the PUREX process, namely the innovative SANEX (i-SANEX) ${ }^{18}$ and the 1-cycle SANEX processes. ${ }^{10,19}$ In i-SANEX it is expected to employ a solvent phase comprising 0.2 M TODGA with 5 vol.\% 1-octanol (corresponding to a concentration of 0.32 M) in an inert diluent. The purpose of adding 1-octanol is to prevent the onset of a third phase. ${ }^{20,21}$ In 1-cycle SANEX the solvent comprises a mixture of $\mathrm{CyMe}_{4} \mathrm{BTBP}$ and $5 \mathrm{mM}$ TODGA in an aliphatic diluent, ${ }^{10}$ in which $\mathrm{CyMe}_{4}$ BTBP designates the 6,6 '-bis $(5,5,8,8$ tetramethyl-5,6,7,8-tetrahydrobenzo[1,2,4]-triazin-3-yl)-[2,2']-bipyridine molecule.

Modeling and simulation are essential tools to design flowsheets efficiently and to test 
the flowsheet against maloperation scenarios, or process upsets. An experimental study of maloperations is not feasible in practice because it would require a huge programme of active pilot plant trials that would be long, hazardous, and very costly. Kinetic data are essential for an accurate simulation of a process flowsheet, but interfacial mass transfer is still one of the most poorly modeled aspects of solvent extraction. This is especially true when considering the case of short residence time centrifugal contactors (with aqueous/organic contact times of a few seconds typically), which is the most likely scenario for future MA separation plants.

In the literature, kinetic data are extremely scarce concerning the transfer of trivalent lanthanide and actinide ions from nitric acid solutions (as commonly used in nuclear reprocessing) by the reference extractants TODGA and $\mathrm{CyMe}_{4}-\mathrm{BTBP}$ in molecular solvents. To our best knowledge, two papers have been published in the case of TODGA, about the extraction of $\mathrm{Am}(\mathrm{III})^{24}$ (using a Lewis cell) and that of Ce(III) ${ }^{25}$ (using a rotating diffusion cell). Besides, one finds a publication in which TODGA was dissolved in an ionic liquid for the extraction of $\mathrm{Eu}(\mathrm{III}) .{ }^{26}$ No reference was found in the case of $\mathrm{CyMe}_{4}$-BTBP.

The research presented in this communication was done within the European project GENIORS (2017-2021). For the development of separation processes, the extraction and stripping kinetics of the lanthanide $\mathrm{Eu}(\mathrm{III})$ ion and the actinide $\mathrm{Am}(\mathrm{III})$ ion were investigated at the interface between nitric acid solutions and organic phases comprising TODGA, or a mixture of $\mathrm{CyMe}_{4}$-BTBP and TODGA, in the diluent TPH ('tétrapropylène hydrogéné', which is a mixture of isomers of dodecane and a widespread diluent in the nuclear industry). The rotating membrane cell (RMC) technique ${ }^{27}$ was employed for the study of the kinetics. The aqueous phase sometimes contained an hydrophilic aqueous ligand, $\mathrm{SO}_{3}-\mathrm{Ph}$ BTP (a sulfonated bis triazinyl pyridine $)^{28}$ or PTD (2,6-bis[1-(propan-1-ol)-1,2,3-triazol-4yl]pyridine), ${ }^{29,30}$ to mimic the conditions of a SANEX process. The PTD molecule is more interesting than $\mathrm{SO}_{3}$-Ph-BTP because, contrary to the latter, it satisfies the CHON principle.

The first aim of this work is to provide kinetic data for these important systems. The results are analyzed from a fundamental point of view, and the practical consequences for in- 
dustrial processes are examined. An additional underlying aim of this study is to interrogate the capability of the technique to provide reliable kinetic data.

This work is organized as follows. The RMC technique is described in the next section. Then the experimental features of this work are exposed, and the results for the transport coefficients (viscosities of the solutions and diffusion coefficients of the solutes) are given. After that, kinetic experiments are reported in conditions of extraction and of stripping independently on the same system. Expectedly, the kinetic rate constants obtained in the two cases should have similar values. These experiments provided a test of the technique and an estimation of the experimental uncertainty with the RMC. After this preliminary study, the extraction and stripping kinetics of $\mathrm{Eu}(\mathrm{III})$ and $\mathrm{Am}(\mathrm{III})$ are investigated in various conditions. The effect of varying the concentration of the extractants, of the aqueous ligands, of nitric acid, and of temperature, is examined. This work ends with a conclusion summarizing the results and exposing some prospects for the future.

\section{Experimental}

\subsection{Overview of experimental techniques}

The RMC possesses the advantage of controlling the hydrodynamics in the two phases. Few techniques possess this property. ${ }^{31}$ The first such technique was devised by a Russian group. ${ }^{32}$ It used a strip of chromatographic paper to stabilize the aqueous phase, that was immersed into the organic phase. Then Albery et al. proposed the rotating diffusion cell (RDC). ${ }^{33}$

The control of transport in the two phases is a fundamental requirement without which no reliable result can be obtained. In this respect, the Lewis cell should not be used, except in the case of very slow kinetics. Otherwise it may yield kinetic rate constants that are

in error by several orders of magnitude. ${ }^{34}$ It was recognized by Danesi (who used this cell extensively) that the plateau region was not necessarily an indication of a kinetic regime 
because of a "slip effect" on the propellers when the rotation speed was increased beyond some value. ${ }^{35}$

Microfluidic devices that ensure direct contact of the phases have been proposed in the past two decades. ${ }^{36}$ However, it is not easy to reliably control the flow and the transport of the species in cells in which the interface is free. It still seems difficult to estimate the contribution from diffusional transport in these cells without making some approximations, in the case of parallel flows ${ }^{37}$ (in which the geometries are not yet simple enough to allow an estimation of the diffusional contribution) as well as moving droplets. ${ }^{38,39}$ As a consequence, these studies generally deliver values for global (apparent) kinetic rate constants combining the effect of the interfacial reaction and diffusional transport in the layers adjacent to the interface.

\subsection{The RMC technique}

\subsubsection{Description of the RMC}

The cell consists of a thin membrane that is glued on the base of a cylinder made of perspex (see Figure 2).
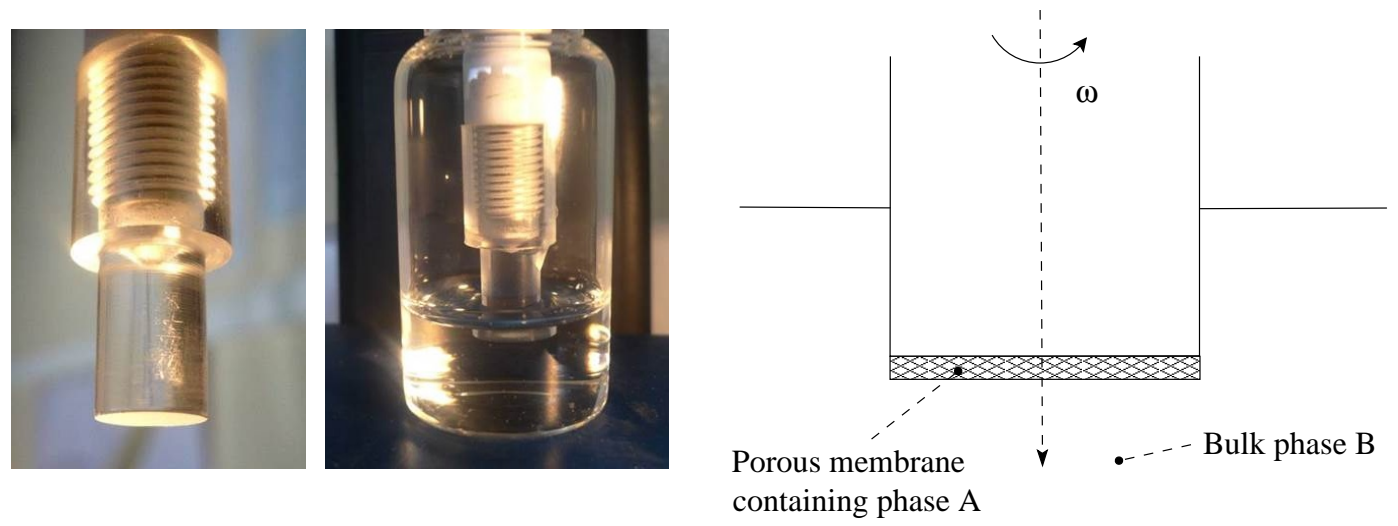

Figure 2: The RMC technique. Left: View of the cell with the membrane glued at the bottom. Center: Cell rotating in the outer phase. Right: Sketch of the technique.

Two types of membranes, one hydrophilic and one hydrophobic, were used in this work to contain the aqueous and organic phases, respectively (see section 2.7). Besides their 
chemical compatibility with the phases, these membranes were selected because they were found to give consistent results for the diffusion coefficients of $\mathrm{Eu}(\mathrm{III})$ measured with the closed capillary technique and the RMC (see Supplementary Information).

The phase contained in the membrane, denoted by A, was spiked with the radioactive tracer to be extracted. The cell was mounted on a rotating-electrode spindle that can be rotated at a definite speed. Initially, it was set into rotation at a known speed and it was immersed into the outer phase B. The rotating electrode was set on a rack that could be lowered or raised easily.

More practical details about the technique are given in the Supporting Information addendum.

\subsubsection{Modeling}

It was assumed that the transfer of solute occurs strictly at the interface between the two phases. This assumption was made because of the very low solubility of extractant in aqueous phases. ${ }^{40}$ This contrasts with a model that was first proposed a few decades ago by the renowned Carl Hanson ${ }^{41,42}$ and later extended by Rod, ${ }^{43}$ in which the complexation reaction may occur in a thin layer in the aqueous phase, adjacent to the interface. This model was not used in the present work.

With the assumption that the complexation reaction is strictly interfacial, the ratio of matter extracted as a function of time can be written as, ${ }^{27}$

$$
P(t)=1-\exp (-t / \tau) \quad \text { or } \quad-\ln [1-P(t)]=t / \tau
$$

where $\tau$ is the mean-passage time of the solute in the overall A-to-B transfer process. It is given by,

$$
\tau=\tau_{A}+\tau_{i}+\tau_{B}
$$

in which $\tau_{A}$ is the mean diffusion time in the membrane (phase $\mathrm{A}$ ), $\tau_{i}$ is the characteristic 
time for the interfacial reaction (from $\mathrm{A}$ to $\mathrm{B}$ ) and $\tau_{B}$ is the mean residence time of solute in the diffusion layer, that results from the competition between the back transfer from B to $\mathrm{A}$ at the interface and removal from the diffusion layer by dilution in B.

The expressions of these times are,

$$
\tau_{A}=L^{2} \theta /\left(3 D_{A}\right) \quad \tau_{i}=L / k_{A \rightarrow B} \quad \tau_{B}=\sigma L \delta_{B} /\left(K_{B / A} D_{B}\right)
$$

in which $L$ is the membrane thickness, $\theta$ is its tortuosity, $D_{A}$ and $D_{B}$ are the solute diffusion coefficients in the bulk of phases $\mathrm{A}$ and $\mathrm{B}$, respectively, $\sigma$ is the membrane porosity, $K_{B / A}=$ $C_{B}^{e q} / C_{A}^{e q}$, and $\delta_{B}$ is the diffusion layer thickness in phase B given by the Levich equation, ${ }^{44}$

$$
\delta_{B}=\frac{1.612}{\mathrm{Sc}^{1 / 3}} \sqrt{\frac{\nu_{B}}{\omega}}
$$

with $\mathrm{Sc}$ the Schmidt number $\left(\mathrm{Sc}=\nu_{B} / D_{B}\right.$, which is commonly of the order of $\left.10^{3}\right), \nu_{B}$ the kinematic viscosity of phase $\mathrm{B}$, and $\omega$ the rotation speed of the membrane (in $\mathrm{rad} \mathrm{s}^{-1}$, $\omega=2 \pi N / 60$ where $N$ is the rotation speed in rpm).

In practice, the value of the diffusion time in the membrane, $\tau_{A}$, is of the order of a few seconds (typically 5-10 s) when the membrane contains the aqueous phase. It is much larger in the case of an organic phase (50-200 s) because then the diffusion coefficient of the solute is much smaller.

In these relations $k_{A \rightarrow B}$ and $k_{B \rightarrow A}$ are the forward (from $\mathrm{A}$ to $\mathrm{B}$ ) and reverse (B to $\mathrm{A}$ ) kinetic rate constants, respectively, and $K_{B / A}$ satisfies the relation, ${ }^{31}$

$$
K_{B / A}=k_{A \rightarrow B} / k_{B \rightarrow A}
$$

When $\mathrm{A}$ is aqueous and $\mathrm{B}$ is organic, then $K_{B / A}$ is the usual organic-to-aqueous distribution ratio, $K$. In that case (extraction), $k_{A \rightarrow B}$ is the extraction rate constant, $k_{e x}$, and $k_{B \rightarrow A}$ is the stripping (back-extraction) rate constant, $k_{s t}$. In the reverse case of stripping ( $\mathrm{A}=\mathrm{org}$, 
$\mathrm{B}=\mathrm{aq})$ then $K_{B / A}=1 / K$, and $k_{A \rightarrow B}=k_{s t}, k_{B \rightarrow A}=k_{e x}$.

By virtue of eq 5 , the time $\tau_{B}$ in eq 3 may be alternatively expressed as,

$$
\tau_{B}=\frac{\sigma k_{B \rightarrow A}}{D_{B} / \delta_{B}} \tau_{i}
$$

which expression highlights the competition between back-transfer of solute into the membrane at a rate $\sigma k_{B \rightarrow A}$ and its removal into B by convective diffusion at a rate $D_{B} / \delta_{B}$.

In the case of infinitely fast interfacial kinetics $\left(k_{A \rightarrow B}\right.$ and $k_{B \rightarrow A} \rightarrow \infty$ with $K_{B / A}$ unchanged), the process becomes diffusion controlled and eq 2 reduces to

$$
\tau_{\infty}=\tau_{A}+\tau_{B}
$$

Replacing $\tau$ by $\tau_{\infty}$ in eq 1 yields the diffusive limit, $P_{\infty}$, of the process.

According to eq 1 a fit of the experimental results for $-\ln [1-P(t)]$ vs. $t$ yields the value of the time $\tau$. Then, the latter may lead to the determination of $k_{A \rightarrow B}$ value (using eqs $2-5)$, which is the only unknown ( $k_{B \rightarrow A}$ being given by eq 5 ), provided all bulk transport parameters (diffusion coefficients, viscosities,...) and the characteristics of the membranes have been determined experimentally.

This technique has been shown to give constant values for the rate constant of transfer of acetic acid when the rotation speed was varied. ${ }^{45}$ This result showed that a good control of the hydrodynamics is achieved with this technique, which avoids the need of prior calibration.

\subsubsection{Use of the RMC in this study}

From a practical point of view, the stripping configuration offers the silver lining of using very small amounts of extractant, since in this case the organic solution is placed in the membrane, which is of very small volume (a few $\mu \mathrm{L}$ ). However, the question arises as to whether the extraction configuration might be preferable when the distribution ratio $K$ is large, which would make the time $\tau_{B}$ very small in eq 3 and therefore provide more accuracy 
in the determination of the kinetic rate constants. This point is illustrated in section 3 below.

By and large, the strategy adopted in this work was to mainly perform stripping experiments and, whenever possible, to carry out a few extraction experiments in order to confirm the result.

\subsection{Chemicals and methods}

The chemical structures of the molecules used in this study are shown in Figure 3.

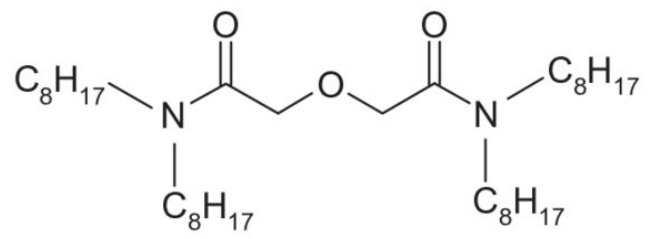

TODGA

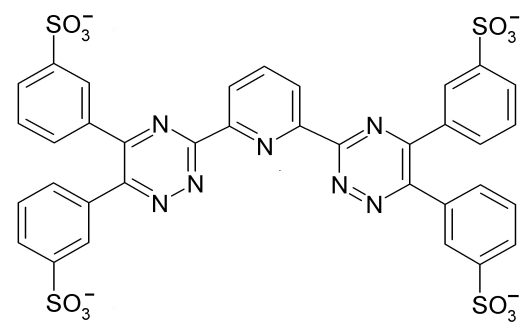

$\mathrm{SO}_{3}-\mathrm{Ph}-\mathrm{BTP}$

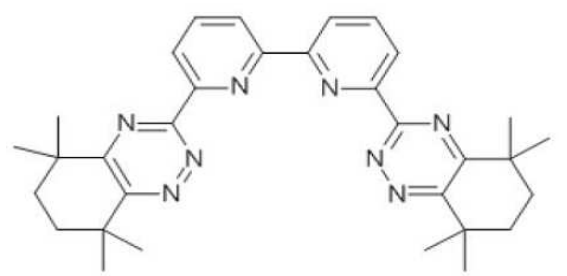

$\mathrm{CyMe}_{4}-\mathrm{BTBP}$

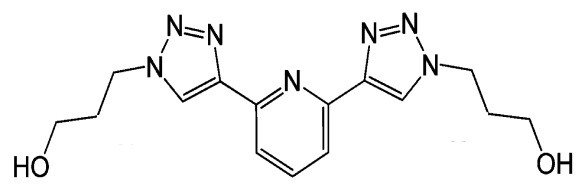

PTD

Figure 3: Chemical structures of the molecules used in this study $\left(\mathrm{SO}_{3}-\mathrm{Ph}-\mathrm{BTP}\right.$ in tetravalent ionic form, counterion: $\mathrm{Na}^{+}$).

The extractants TODGA and PTD, were synthesized by authors of this work (at Twente and Parma, respectively). ${ }^{29,46}$ The extractant $\mathrm{CyMe}_{4}$-BTBP and the complexing agent $\mathrm{SO}_{3^{-}}$ Ph-BTP were synthesized by Karlsruhe Institute for Technology (KIT). The $\mathrm{SO}_{3}$-Ph-BTP was provided and used as the tetra-sodium salt. The TPH diluent was provided by CEA (purchased from NOVASEP). These compounds were used as received. The ${ }^{152} \mathrm{Eu}(\mathrm{III})$ and 
${ }^{241} \mathrm{Am}$ (III) radioactive sources were purchased from ORANO-LEA (France). Aqueous solutions were prepared with ultrapure water (Millipore, $18.2 \mathrm{M} \Omega \mathrm{cm}$ ). All other chemicals were purchased from AnalaR (Normapur), Sigma-Aldrich and Fluka, and were used without further purification.

A small amount of 1-octanol (5 vol.\%, which corresponds to $0.32 \mathrm{M}$ ) was added to the TPH diluent in order to prevent the formation of a third phase. Hereafter, for convenience, this solvent will be designated by the abbreviation TPH-O.

The organic phases were pre-equilibrated with the aqueous phase prior to a kinetic experiment, in order to saturate the organic phase with water and nitric acid. The aqueous phases were not pre-equilibrated with the organic phase (the equilibrium concentration of 1-octanol in the aqueous phases was neglected). In contrast, in the kinetic experiments with 1-octanol as the diluent, the two phases were pre-equilibrated with each other because 1-octanol is slightly soluble in the aqueous phase $\left(\sim 4 \times 10^{-3} \mathrm{M}\right.$ in water at $\left.25^{\circ} \mathrm{C}\right)$.

The distribution ratios were determined by equilibrating $500 \mu \mathrm{L}$ of the two phases in a 5 mL vial made of Teflon. The phases were highly stirred during 1 to 4 hours. After centrifugation, aliquots of the two phases $(350 \mu \mathrm{L})$ were separated and their activities were measured using a gamma counter, Packard Cobra II Auto Gamma (calibrated weekly, according to the standard procedure using a ${ }^{137} \mathrm{Cs}$ calibration source of $\left.9435 \mathrm{~Bq}\right)$.

In this work, the RMC was rotated at a speed of $600 \mathrm{rpm}$, and the diffusion and extraction experiments were carried out at a temperature of $22 \pm 1^{\circ} \mathrm{C}$, unless otherwise indicated.

\subsection{Solute diffusion coefficients}

The bulk transport parameters and the characteristics of the membranes are key parameters that must be determined experimentally.

No data for the diffusion coefficient of $\mathrm{Eu}(\mathrm{III})$ and $\mathrm{Am}(\mathrm{III})$ were found in the literature in the case of our systems. The diffusion coefficients of Eu(III) were determined using the closed capillary technique suitable for a $\gamma$-emitter, ${ }^{47,48}$ and the RMC. Typical results are shown in 
Figures S1 and S2. The diffusion coefficients of ${ }^{241} \mathrm{Am}$ (III) could not be determined with the capillary technique because it is a $\gamma$-emitter of low energy, which would impose the use of a too large amount of tracer for a reliable measurement to be done.

In the case of the RMC, identical solutions A and B (see Figure 2) were employed, except for the diffusing solute which was present in A only. The porosity and the tortuosity of a membrane are required for the determination of the $D$ 's. They were assessed as described below in section 2.7 .

The measurement of a diffusion coefficient with the RMC typically lasts 10 seconds for an aqueous solution, and 1 minute for an organic solution, as compared to several days with the closed capillary technique. Nevertheless, the RMC requires a larger amount of solution (of the order of 2 or $3 \mathrm{~mL}$ ) than the capillary technique (less than $100 \mu \mathrm{L}$ ). Similar results for the $D$ values were obtained with the two techniques in the case of $\mathrm{Eu}(\mathrm{III})$ (see Supporting Information).

The Stokes hydrodynamic radii values, $R$, of $\mathrm{Eu}(\mathrm{III})$ and $\mathrm{Am}(\mathrm{III})$ ions may be derived from the $D$ values by using the Stokes-Einstein equation in the form,

$$
R=k_{B} T /(6 \pi \eta D)
$$

with $k_{B}$ the Boltzmann constant, $T$ the temperature, and $\eta$ the dynamic viscosity of water or of the organic diluent (the medium in the vicinity of the complex) at temperature $T$. The hydrodynamic radius $R$ provides an estimation of the size of the complex in solution.

The results for the diffusion coefficients are gathered in the Supporting Information.

\subsection{Diffusion coefficients measured using NMR}

Initially, it was planned to measure the self-diffusion coefficients of (inactive) $\mathrm{Eu}$ (III) by using NMR (nuclear magnetic resonance). ${ }^{49}$ However, this was not possible because the europium nucleus is paramagnetic. It was not possible to make this measurement for the 
diamagnetic lanthanum nucleus either, because its resonance frequency is very close to that of deuterium (used for the lock in our NMR spectrometer). Then the lock filter blocked the signal produced by the lanthanum nucleus.

The diffusion coefficients of the solvent species in solutions of TODGA + 1-octanol in TPH were investigated by using NMR. Most experiments were carried out in presence of lanthanide $(\mathrm{Ln})$ ions, $\mathrm{Eu}(\mathrm{III})$ and $\mathrm{La}(\mathrm{III})$, at a fixed concentration of $0.02 \mathrm{M}$ (in the form of Ln-nitrate). La(III) was used in addition to $\mathrm{Eu}(\mathrm{III})$ in order to confirm the results obtained with the latter. For comparison, some experiments were conducted in the absence of Ln ions, at $0.06 \mathrm{M}$ and $0.2 \mathrm{M}$ TODGA. All solutions were pre-equilibrated with a $0.5 \mathrm{M} \mathrm{HNO}_{3}$ solution (prior to the incorporation of $\operatorname{Ln}(\mathrm{III})$ ).

The technical details of these experiments and the results are presented in the Supporting Information.

\subsection{Solution viscosities}

The values of the kinematic viscosities of the solutions, $\nu$, are required in the analysis of the kinetic data, and those of the dynamic viscosity, $\eta$, are needed for the calculation of the Stokes radii.

The values of $\eta$ at $22^{\circ} \mathrm{C}$ were measured using an Anton Paar AMVn Automated Micro Viscometer. The data at $22^{\circ} \mathrm{C}$, and those estimated at $35^{\circ} \mathrm{C}$, are collected in the Supporting Information.

\subsection{Membranes}

The physical characteristics of the membranes, thickness $L$, porosity $\sigma$, and tortuosity $\theta$, are needed in the treatment of the experimental data.

Two types of membranes were purchased from Merck Millipore: the hydrophilic Omnipore PTFE membrane (JHWP04700, manufacturer's data: pore size $0.45 \mu \mathrm{m}$, porosity of $80 \%$ ) was employed to contain aqueous solutions, and the hydrophobic Durapore PVDF 
membrane (HVHP04700, manufacturer's data: pore size $0.45 \mu \mathrm{m}$, porosity of $75 \%$ ) was employed for organic solutions. The porosity values were also measured by impregnating membranes (glued on a plastic cylinder) with TPH and by measuring the corresponding mass of diluent. The membrane thicknesses, $L$, were measured by using a digital micrometer.

The tortuosities of the two types of membrane were obtained as follows. First the diffusion coefficient of $\mathrm{Eu}(\mathrm{III})$ ion was measured by using the closed capillary technique (with a capillary of $3 \mathrm{~cm}$ total length), in the case of a $3 \mathrm{M} \mathrm{HNO}_{3}$ aqueous solution for the hydrophilic membrane, and in the case of a 0.2 M TODGA organic solution in TPH-O solvent pre-equilibrated with a $3 \mathrm{M} \mathrm{HNO}_{3}$ solution. In a second step diffusion experiments were carried out with the RMC for the same systems, with identical solutions A and B (A $\equiv$ $\mathrm{B}$, aqueous or organic). The tortuosity value of a membrane was then adjusted so as to recover the experimental data obtained with the RMC, and by using the $D$ value for $\operatorname{Eu}($ III) measured using the closed capillary technique. The adjustment was performed by employing the formula for $P_{\infty}$, eq 1 together with eq 7 and taking $K_{B / A}=1$.

This methodology relies on the consideration that the pores of the membranes are of macroscopic size $(\sim 0.45 \mu \mathrm{m}$ according to the manufacturer). This feature allows one to consider the diffusion process of an ion in the pores as being of the same nature as diffusion in the bulk solution (no effect of confinement).

The values of $L, \sigma$, and $\theta$ are collected in Table 2 . These values were used for the subsequent determination of the diffusion coefficients of the solutes in other solutions and of the kinetic rate constants with the RMC technique.

Table 2: Physical characteristics of the membranes.

\begin{tabular}{lccc}
\hline Type of membrane & Membrane thickness & Porosity & Tortuosity \\
& $L / \mu \mathrm{m}$ & $\sigma$ & $\theta$ \\
\hline Hydrophilic JHWP04700 & 58 & 0.80 & 2.51 \\
Hydrophobic HVHP04700 & 102 & 0.75 & 1.94 \\
\hline
\end{tabular}

The membranes were glued on the base of the plastic cylinder with liquid Kapton (a 
polyimide purchased from Aldrich: Pyre-ML RC-5019, CAS no. 25038-81-7). Moreover, the lower part of the plastic cylinder was covered with Kapton in order to isolate its surface from the solutions (especially organic). Kapton was chosen because it is known to have very weak interactions with most compounds.

\section{$3 \quad$ Kinetic rate constants from extraction and stripping experiments}

As mentioned in section 2.2.3, the kinetic rate constants were determined by carrying out preferentially stripping experiments. Additionally, a few extraction experiments were performed to confirm the results, when the extractant was available in sufficient amount (a kinetic extraction experiment consumes about 500 times more extractant than a stripping experiment).

So the question arises of whether the two configurations yield consistent values for the kinetic rate constants. In this section, this problem is illustrated in the case of a system exhibiting a high value of the distribution ratio $K$. This system was comprised of $0.2 \mathrm{M}$ TODGA in TPH-O solvent (pre-equilibrated with a $0.5 \mathrm{M} \mathrm{HNO}_{3}$ solution) as the organic phase, and a $0.5 \mathrm{M} \mathrm{HNO}_{3}$ solution as the aqueous. For this system one has $K=329$. This high $K$ value makes this system an extreme case to study.

Figure 4 and Table 3 show the results obtained for the rate constants.

Table 3: Characteristic times, contrast parameter, and extraction and stripping kinetic rate constants obtained from extraction and stripping experiments, for the solutions of Figure 4.

\begin{tabular}{llcccccc}
\hline & $K_{B / A}$ & $\tau_{A}(/ \mathrm{s})$ & $\tau_{B}(/ \mathrm{s})$ & $\tau_{i}(/ \mathrm{s})$ & $C$ & $k_{e x}\left(\mathrm{~cm} \mathrm{~s}^{-1}\right)$ & $k_{s t}\left(\mathrm{~cm} \mathrm{~s}^{-1}\right)$ \\
\hline Extraction & 329 & 5.27 & 0.0135 & 2.54 & 0.32 & $2.28 \times 10^{-3}$ & $6.95 \times 10^{-6}$ \\
Stripping & 0.00304 & 54.3 & 768 & 1617 & 0.66 & $2.07 \times 10^{-3}$ & $6.31 \times 10^{-6}$ \\
\hline
\end{tabular}

Figure 4 shows that extraction (left) exhibits much faster kinetics than the stripping experiment (right). The minimum duration of an extraction experiment was $\sim 5 \mathrm{~s}$. 

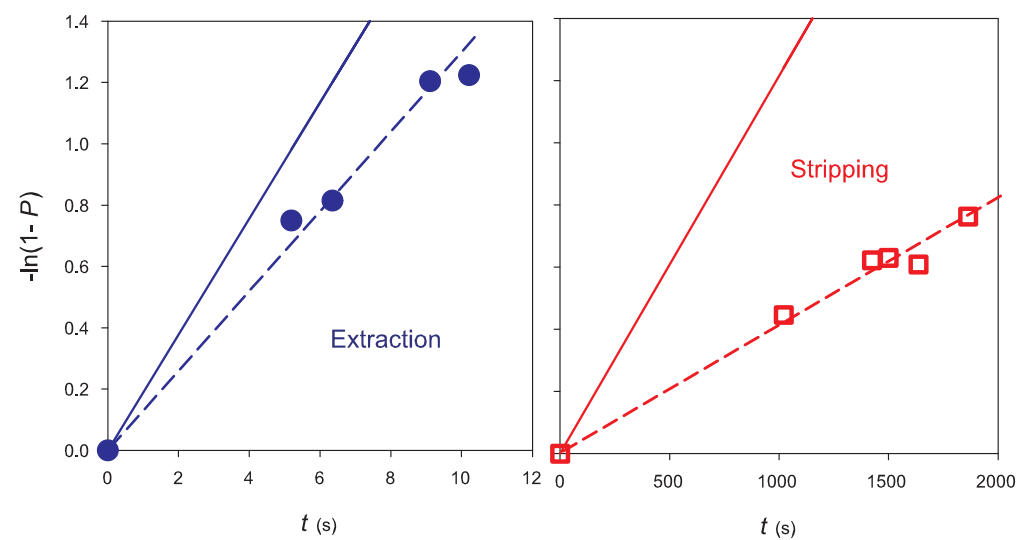

Figure 4: Proportion of extracted ${ }^{152} \mathrm{Eu}(\mathrm{III}), P$, as a function of time in the case of extraction (left) and stripping (right) experiments. Aqueous phase $=0.5 \mathrm{M} \mathrm{HNO}_{3}$. Organic phase $=$ 0.2 M TODGA in TPH-O. Dashed lines = fit of experimental data using eq 1; solid lines = diffusive limit (eqs 1 and 7 ).

The characteristic times of transfer, $\tau$, had values of $\sim 7.8 \mathrm{~s}$ and $2440 \mathrm{~s}$ in the extraction and stripping cases, respectively. The difference is due to the much higher values of $\tau_{A}, \tau_{B}$, and $\tau_{i}$ in the stripping case (see Table 3 ). These high values originate from the lower diffusion coefficient in the organic phase, and from the low values of $K_{a q / o r g}$, and $k_{s t}$, respectively.

The experimental points are closer to the diffusive limit (DL) in the extraction configuration. The distance between the two reflects the effect of the interfacial reaction which slows down the transfer of the ion across the interface. The larger relative distance in the case of stripping entails that the accuracy of the rate constant determination should be higher than in the extraction experiment.

This distance may be quantified by defining a contrast parameter as the relative difference between the slopes, $C=-\left(\tau^{-1}-\tau_{\infty}^{-1}\right) / \tau_{\infty}^{-1}$, which by virtue of eqs 2 and 7 may be rewritten as

$$
C=\frac{\tau_{i}}{\tau}
$$

The values of $C$ are given in Table 3 in the present case.

It can be seen in Table 3 that the rate constants $k_{e x}$ and $k_{s t}$ obtained in the two exper- 
imental configurations are comparable, with a discrepancy of $\sim 10 \%$. In other experiments of the same type, with other systems, the discrepancy could sometimes reach $\sim 20 \%$. These values give an order of magnitude of the experimental uncertainty.

This may seem a rather large uncertainty. However, the extraction and stripping experiments were carried out using two different types of membrane. Moreover, experimental kinetic rate constants may be in error by several orders of magnitude if the hydrodynamics and the diffusive transport are not well controlled. Therefore an uncertainty of $10 \%$ or $20 \%$ is actually small in comparison of what it can be when an unsuitable technique is used. It also reflects the intrinsic difficulty of determining L/L interfacial kinetic rate constants.

In view of this uncertainty value, the results for the rate constant will hereafter be given with two significant figures only.

\section{Kinetics with TODGA in TPH-O}

\subsection{Effect of TODGA concentration}

The influence of the TODGA concentration on the transfer kinetics of ${ }^{152} \mathrm{Eu}(\mathrm{III})$ was investigated. Figure 5 shows the results for the distribution ratio $K$ and the kinetic rate constants. The numerical values are given in the Supporting Information.

One notes in Figure 5 that, when the TODGA concentration was increased from $0.1 \mathrm{M}$ to $0.4 \mathrm{M}$, the distribution ratio $K$ was highly enhanced, showing a strong complexation by TODGA. Since the distribution ratio is high for every TODGA concentration, extraction experiments were conducted exceptionally in this case, because stripping experiments would have been accompanied by a larger uncertainty in the values of the rate constants (due to a high influence of the transport process in the outer aqueous phase).

The stripping rate constant $\left(k_{s t}\right)$ is rather small (of the order of a few $10^{-6}$ or $10^{-5}$ $\left.\mathrm{cm} \mathrm{s}^{-1}\right)$. It was considerably reduced by an increase in the concentration of TODGA. At the same time, the extraction rate $\left(k_{e x}\right)$ is rather high (a few $10^{-3} \mathrm{~cm} \mathrm{~s}^{-1}$ ) and it dropped 
notably with [TODGA]. Since the extraction rate of Am(III) is equally fast (see Table 4), this implies that the co-extraction stage of $\mathrm{Eu}(\mathrm{III})$ and $\mathrm{Am}(\mathrm{III})$ by TODGA (top of Figure 1) should be fast in the industrial process.

A log-log plot of $K$ (see Figure S5), $k_{e x}$, and $k_{s t}$ (not shown for the rate constants) indicates approximately linear variations with slopes of $\sim 1.5,-0.4$, and -1.9 , respectively. This dependency suggests a number of TODGA molecules between 1 and 2 per Eu(III) ion. This result is lower than slopes of $\sim 3.2$ and $\sim 3.7$ found previously in the literature in the case of $1 \mathrm{M} \mathrm{HNO}_{3}$ and lower TODGA concentration in $n$-dodecane (ranging from $0.01 \mathrm{M}$ to $0.1 \mathrm{M}$ ) without 1 -octanol. ${ }^{50,51}$ This discrepancy may be due to the different experimental conditions (nitric acid and TODGA concentrations, use of TPH instead of dodecane, and presence of 1-octanol in our measurements), and to the fact that the slope of the log-log plot of $K$ in Figure S5 is expected to be larger for TODGA concentrations below $0.1 \mathrm{M}$ in our system.

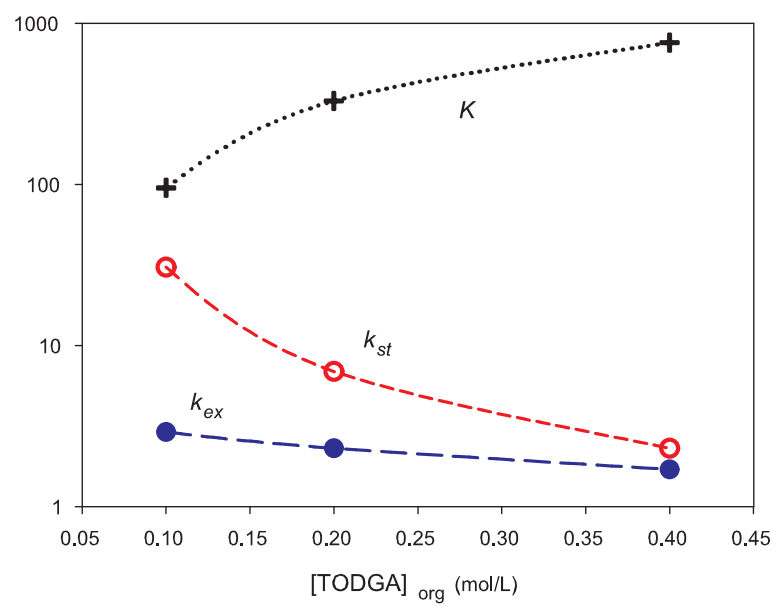

Figure 5: Results for ${ }^{152} \mathrm{Eu}(\mathrm{III})$ as a function of [TODGA] in organic phase (log plot on vertical axis): $(+)=$ Distribution ratio $K,(\bullet)=k_{e x}$ in units of $10^{-3} \mathrm{~cm} \mathrm{~s}^{-1},(\bigcirc)=k_{s t}$ in units of $10^{-6} \mathrm{~cm} \mathrm{~s}^{-1}$. Organic phase: TODGA in TPH-O. Aqueous phase: $0.5 \mathrm{M} \mathrm{HNO}_{3}$.

In order to get more insight into these results, interfacial tension measurements were performed by using Lecomte du Noüy ring method. The result is shown in Figure 6 .

This plot shows that TODGA is surface active in TPH in the absence of 1-octanol 


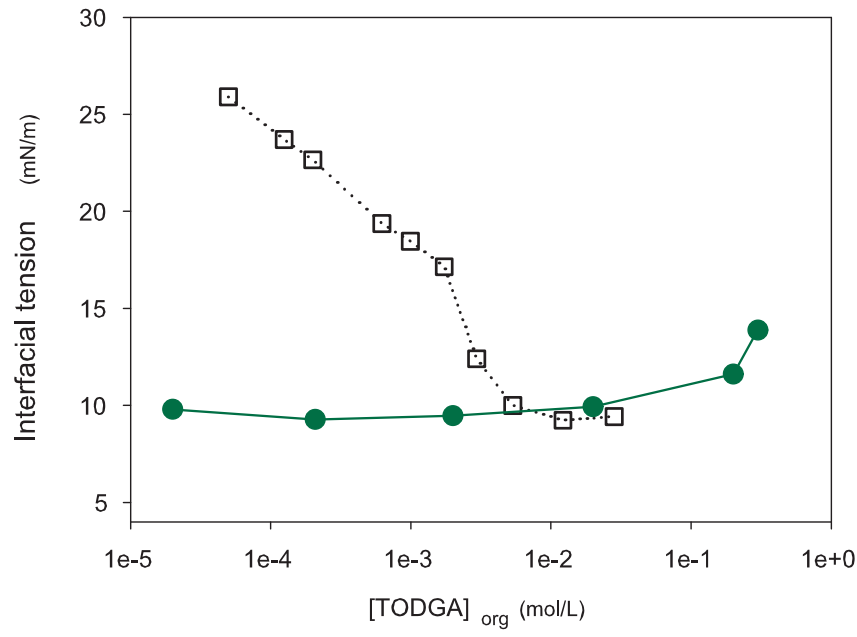

Figure 6: Interfacial tension at the interface: $3 \mathrm{M} \mathrm{HNO}_{3}$ aqueous solution/organic phase, vs. TODGA concentration at $22^{\circ} \mathrm{C}$. $(\square)=$ Organic phase comprised of TODGA in TPH; $(\bullet)=$ Organic phase comprised of TODGA in TPH-O.

(represented by squares in Figure 6), and that it is not surface active in the presence of 5 vol.\% 1-octanol (full circles). These findings suggest that 1-octanol may replace TODGA at the interface when it is introduced in TPH. This interpretation is reinforced by the experimental observation that TODGA is not surface active when it is dissolved in pure 1-octanol (not shown).

Consequently, the slowdown of the kinetics observed in Figure 5 is counterintuitive, because one may expect the extraction process to be faster when more extractant is present in the organic phase, as has been for example observed in the past in a system involving dithizone as the extractant, which exhibited no surface activity. ${ }^{52}$ Indeed, one may expect that more TODGA in the organic phase would increase the probability of a TODGA molecule to reach the interface, hence also the encounter between an Eu(III) ion and a TODGA molecule there, which would accelerate the transfer. The fact that it is not so, and that both the extraction and back-extraction processes are affected, may be related to the aggregation properties of TODGA in the organic phase, ${ }^{53}$ a phenomenon which does not occur in the case of dithizone. Nevertheless the precise way in which aggregation may cause the slowdown of the kinetics is unclear at present. This topic would require further experimental 
investigations.

\subsection{Effect of $\mathrm{HNO}_{3}$ concentration}

The effect of nitric acid concentration needs be investigated. ${ }^{152} \mathrm{Eu}(\mathrm{III})$ and ${ }^{241} \mathrm{Am}(\mathrm{III})$ were extracted from $0.5 \mathrm{M}$ and $3 \mathrm{M} \mathrm{HNO}_{3}$ solutions into a $0.2 \mathrm{M}$ TODGA solution in TPH-O. The results for the distribution ratio and the kinetic rate constants are collected in Table 4 . Table 4: Distribution ratios and kinetic rate constants for ${ }^{152} \mathrm{Eu}(\mathrm{III})$ and ${ }^{241} \mathrm{Am}$ (III) at the interface between 0.2 M TODGA in TPH-O and $\mathrm{HNO}_{3}$ solutions of different concentrations.

\begin{tabular}{lrrll}
\hline Cation & Aqueous phase & $K$ & $\begin{array}{l}k_{\text {ex }}\left(\mathrm{cm} \mathrm{s}^{-1}\right) \\
\text { aq } \rightarrow \text { org }\end{array}$ & $\begin{array}{l}k_{s t}\left(\mathrm{~cm} \mathrm{~s}^{-1}\right) \\
\text { org } \rightarrow \mathrm{aq}\end{array}$ \\
\hline${ }^{152} \mathrm{Eu}(\mathrm{III})$ & $0.5 \mathrm{M} \mathrm{HNO}_{3}$ & 329 & $2.4 \times 10^{-3}$ & $6.9 \times 10^{-6}$ \\
& $3 \mathrm{M} \mathrm{HNO}_{3}$ & 1044 & $3.1 \times 10^{-3}$ & $3.0 \times 10^{-6}$ \\
${ }^{241} \mathrm{Am}(\mathrm{III})$ & $0.5 \mathrm{M} \mathrm{HNO}_{3}$ & 58 & $2.8 \times 10^{-3}$ & $4.8 \times 10^{-6}$ \\
& $3 \mathrm{M} \mathrm{HNO}_{3}$ & 2977 & $3.9 \times 10^{-3}$ & $1.3 \times 10^{-6}$ \\
\hline
\end{tabular}

As seen in this table, the distribution ratios $K$ for $\mathrm{Eu}(\mathrm{III})$ and $\mathrm{Am}$ (III) were found to be strongly enhanced when $\left[\mathrm{HNO}_{3}\right]$ was varied from $0.5 \mathrm{M}$ to $3 \mathrm{M}$ (by factors of $\sim 3.2$ and 51, respectively). This behavior is in keeping with previous work. ${ }^{50}$ It may be interpreted along the Le Châtelier principle because the extracted complex contains nitrate ions, ${ }^{50}$ and maybe also nitric acid molecules as in the case of other extractants. ${ }^{54}$

In contrast, the extraction rate constants, $k_{e x}$, for $\mathrm{Eu}(\mathrm{III})$ and $\mathrm{Am}(\mathrm{III})$ were increased but they did not vary as much as $K$ did. They were of comparable high magnitudes for the two species, with $k_{e x}$ values of a few $10^{-3} \mathrm{~cm} \mathrm{~s}^{-1}$. They increased by about $30 \%$ when $\left[\mathrm{HNO}_{3}\right]$ was changed from $0.5 \mathrm{M}$ to $3 \mathrm{M}$. This acceleration may be attributed to a higher rate of encounter for a $\mathrm{Eu}(\mathrm{III})$ or $\mathrm{Am}(\mathrm{III})$ ion with a nitrate ion and a nitric acid molecule (which combine to form the extracted complex ${ }^{50}$ ) when the acid concentration is increased.

On the other hand, the stripping of these cations from TODGA solution to aqueous nitric acid was slow with $k_{s t}$ values of the order of a few $10^{-6} \mathrm{~cm} \mathrm{~s}^{-1}$. Moreover, the stripping rate constants dropped by $\sim 60 \%$ and $70 \%$ in the case of $\mathrm{Eu}(\mathrm{III})$ and $\mathrm{Am}(\mathrm{III})$, respectively, when $\left[\mathrm{HNO}_{3}\right]$ was increased from $0.5 \mathrm{M}$ to $3 \mathrm{M}$. This slowdown may be caused by a more difficult 
release of nitrate or nitric acid from the complex, at the interface, when nitric acid is more concentrated in the aqueous phase.

These results suggest that, in the industrial process, the co-extraction of lanthanides and actinides should be performed from concentrated nitric acid solutions $(\geq 3 \mathrm{M})$ that will favor both the partitioning (higher $K$, which is well known) and the extraction kinetics (higher $k_{e x}$ and lower $k_{s t}$ ) of the elements.

\section{Kinetics of stripping in the presence of aqueous lig- ands}

The $\mathrm{SO}_{3}-\mathrm{Ph}-\mathrm{BTP}^{28}$ and $\mathrm{PTD}^{29}$ molecules are promising aqueous ligands envisaged for the SANEX and GANEX An/Ln separation processes. ${ }^{55}$ The effect of these ligands on the kinetics of stripping of $\mathrm{Eu}(\mathrm{III})$ and $\mathrm{Am}(\mathrm{III})$ was investigated.

\subsection{Addition of $\mathrm{SO}_{3}-\mathrm{Ph}-\mathrm{BTP}$}

\subsubsection{Effect of $\mathrm{SO}_{3}-\mathrm{Ph}-\mathrm{BTP}$ concentration}

Figure 7 shows the results for the inverse of the distribution ratios, $1 / K=C_{a q}^{e q} / C_{o r g}^{e q}$ of $\mathrm{Eu}(\mathrm{III})$ and Am(III) between an organic 0.2 M TODGA solution in TPH-O and an aqueous $0.5 \mathrm{M}$ $\mathrm{HNO}_{3}$ solution for concentrations of $\mathrm{SO}_{3}$-Ph-BTP in the aqueous phase up to $40 \mathrm{mM}$. Figures 8 and S6 give the corresponding results for the stripping and extraction rate constants, respectively. The values of these quantities are given in the Supporting Information.

As expected, an increase of $\left[\mathrm{SO}_{3}-\mathrm{Ph}-\mathrm{BTP}\right]_{a q}$ strongly increased the aqueous-to-organic distribution ratio $1 / K$ of $\mathrm{Eu}(\mathrm{III})$ and $\mathrm{Am}(\mathrm{III})$ (see Figure 7) because the ligand tends to capture the solute in the aqueous phase. It is seen in Table S8 that the addition of only 10 $\mathrm{mM} \mathrm{SO}_{3}$-Ph-BTP produces a rise of the value of $1 / K$ by a factor of $\sim 3$ and $\sim 400$ in the case of $\mathrm{Eu}(\mathrm{III})$ and $\mathrm{Am}(\mathrm{III})$, respectively. Then doubling the concentration of the aqueous ligand 


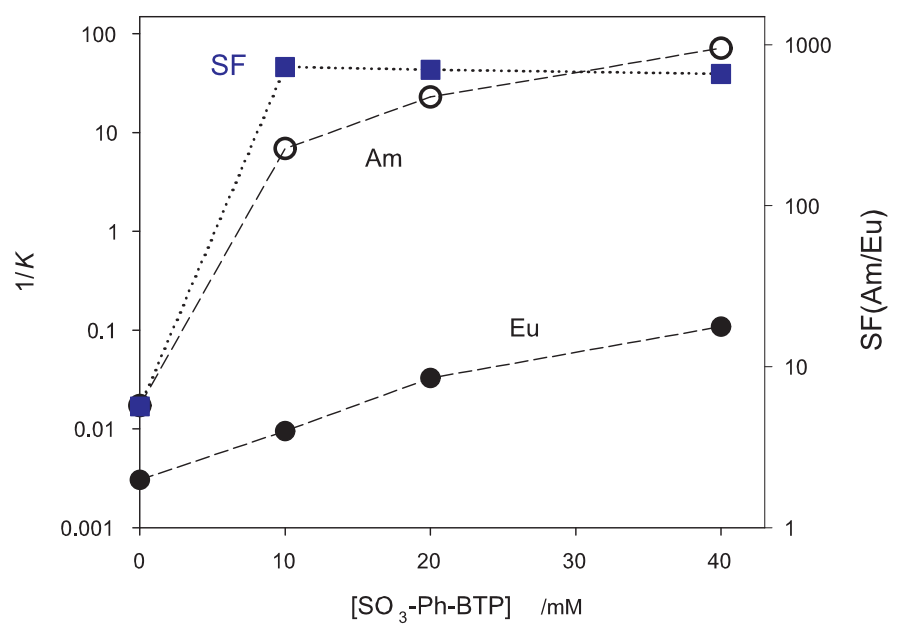

Figure 7: Aq/org distribution ratios (1/K, left scale), and separation factor ( $\mathrm{SF}(\mathrm{Am} / \mathrm{Eu})$, right scale), of $\mathrm{Eu}(\mathrm{III})$ and $\mathrm{Am}(\mathrm{III})$ for an organic $0.2 \mathrm{M}$ TODGA solution in TPH-O and an aqueous $0.5 \mathrm{M} \mathrm{HNO}_{3}$ solution as a function of $\mathrm{SO}_{3}$-Ph-BTP concentration in aqueous phase up to $40 \mathrm{mM}$. $(\bullet)=\mathrm{Eu}(\mathrm{III}) ;(\bigcirc)=\mathrm{Am}(\mathrm{III})$.

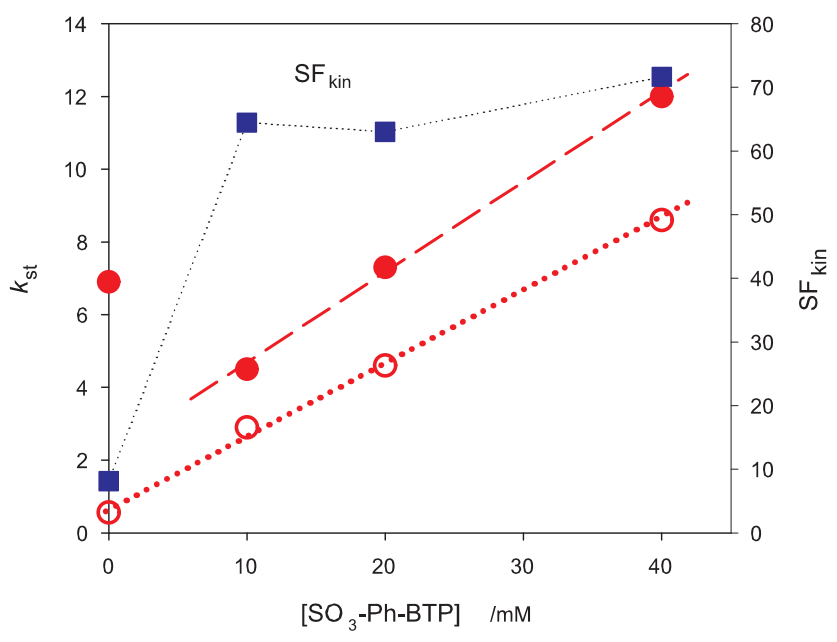

Figure 8: Stripping rate constants (left scale), and kinetic separation factor ( $\mathrm{SF}_{k i n}$, right scale), for $\mathrm{Eu}(\mathrm{III})$ (in $10^{-6} \mathrm{~cm} \mathrm{~s}^{-1}$ ) and Am(III) (in $10^{-4} \mathrm{~cm} \mathrm{~s}^{-1}$ ) for the system considered in Figure 7. (•) $=\mathrm{Eu}(\mathrm{III}) ;(\bigcirc)=\mathrm{Am}(\mathrm{III})$ 
causes $1 / K$ to be increased by a factor of approximately 3 in both cases. This is reflected in the fact that the variation of $1 / K$ is nearly linear in log-log scale (not shown) with a slope of $\sim 1.7$ for the two ions. This slope seems a little small in absolute value in view of reported association constants for the possible ligand-metal complexes, ${ }^{56}$ which would suggest a slope between 2 and 3. Deviations from ideality involving the highly charged $\mathrm{SO}_{3}$-Ph-BTP ion (see Figure 3) in the aqueous phase might be partly responsible for the difference.

The Am/Eu separation factors, $\mathrm{SF}(\mathrm{Am} / \mathrm{Eu})=(1 / K(\mathrm{Am})) /(1 / K(\mathrm{Eu}))=K(\mathrm{Eu}) / K(\mathrm{Am})$

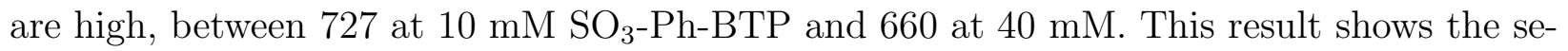
lectivity of the aqueous ligand $\mathrm{SO}_{3}$-Ph-BTP towards the actinide $\mathrm{Am}(\mathrm{III})$ through stripping.

It is observed in Figure 8 that the stripping rates for both ${ }^{152} \mathrm{Eu}(\mathrm{III})$ and ${ }^{241} \mathrm{Am}(\mathrm{III})$ exhibit a linear increase by addition of $\mathrm{SO}_{3}$-Ph-BTP. In the case of $\mathrm{Eu}(\mathrm{III}), k_{s t}$ initially drops between $0 \mathrm{mM}$ and $10 \mathrm{mM} \mathrm{SO}_{3}$-Ph-BTP before increasing linearly. The $k_{s t}$ value for Am(III) increases continuously over the whole range. With $k_{s t}$ values of ${ }^{241} \mathrm{Am}(\mathrm{III})$ in the range of $10^{-4}$ to $10^{-3} \mathrm{~cm} \mathrm{~s}^{-1}$, the stripping rate for ${ }^{241} \mathrm{Am}$ (III) was rather fast, and greatly faster than for ${ }^{152} \mathrm{Eu}(\mathrm{III})$. The ratio of the stripping rate constants, $k_{s t}(\mathrm{Am}) / k_{s t}(\mathrm{Eu})$, varies from 63 for $10 \mathrm{mM} \mathrm{SO}_{3}$-Ph-BTP to 118 for $40 \mathrm{mM} \mathrm{SO}$-Ph-BTP.

The behavior of the stripping rate constant vs. $\left[\mathrm{SO}_{3}-\mathrm{Ph}-\mathrm{BTP}\right]$ makes a case for a mechanism in which the aqueous ligand captures the ion at the interface with a velocity that is proportional to its concentration. This may be expressed by writing $k_{s t}=k_{s t}^{(0)}+\lambda L$, for $L \geq 10 \mathrm{mM}$, with $L=\left[\mathrm{SO}_{3}-\mathrm{Ph}-\mathrm{BTP}\right]$, in which $k_{s t}^{(0)}$ and $\lambda$ are constants.

A look at Table S8 shows that the extraction kinetic rate constants have moderate values and are considerably lower for both ${ }^{152} \mathrm{Eu}(\mathrm{III})$ and ${ }^{241} \mathrm{Am}(\mathrm{III})$ when $\left[\mathrm{SO}_{3}-\mathrm{Ph}-\mathrm{BTP}\right]_{a q}$ is added, especially in the case of $\mathrm{Am}(\mathrm{III})$. In the presence of $10 \mathrm{mM}$ aqueous ligand, the values of $k_{e x}$ for the two ions are reduced by a factor of $\sim 5$ and 80 , respectively, as compared to a ligand-free solution. For each value of $\left[\mathrm{SO}_{3}-\mathrm{Ph}-\mathrm{BTP}\right]_{a q}$, the extraction rate constant $k_{e x}$ for ${ }^{152} \mathrm{Eu}(\mathrm{III})$ is observed to be about 10 times that for ${ }^{241} \mathrm{Am}(\mathrm{III})$.

It may be added that the ligand $\mathrm{SO}_{3}-\mathrm{Ph}-\mathrm{BTP}$ does not accelerate the extraction kinetics 
of $\mathrm{Eu}(\mathrm{III})$ and $\mathrm{Am}(\mathrm{III})$. Such an acceleration had been observed in the literature, e.g. by the acetate anion on the extraction of divalent cations like $\mathrm{Co}(\mathrm{II}) .{ }^{57-59}$ An interpretation of this phenomenon was that the ligand may replace water molecules bound to the metal aquo-ion to form a kinetically more labile complex. ${ }^{57,58}$ The reverse situation is observed in the present case, with a ligand that binds very hard to the ion and slows down its kinetics of extraction.

From the important point of view of applications for the industrial processes SANEX and GANEX, it is interesting to look at the kinetic selectivity of the ligand in a stripping stage. This may be done by computing a stripping kinetic Am/Eu separation factor, defined as,

$$
\mathrm{SF}_{k i n}=k_{s t}(\mathrm{Am}) / k_{s t}(\mathrm{Eu})
$$

which quantity allows one to compare the respective fluxes of Am and Eu when an organic phase loaded with these elements is put in contact with a fresh aqueous solution.

The values of $\mathrm{SF}_{k i n}$ are plotted in Figure 8. It is seen that this kinetic separation factor is strongly enhanced by addition of ligand, as is the separation factor at equilibrium, SF.

Therefore the separation of $\mathrm{Am}(\mathrm{III})$ from $\mathrm{Eu}(\mathrm{III})$ by stripping is greatly enhanced by $\mathrm{SO}_{3}$-Ph-BTP, both thermodynamically and kinetically. This outcome will likely be quite favorable for An/Ln separation using short-time phase contacting extractors in SANEX and GANEX processes.

\subsubsection{Effect of $\mathrm{HNO}_{3}$ concentration (in the presence of $\mathrm{SO}_{3}-\mathrm{Ph}-\mathrm{BTP}$ )}

In the extraction processes envisaged for the future, actinides may have to be re-extracted from aqueous solutions containing a hydrophilic ligand (e.g., $\mathrm{SO}_{3}$-Ph-BTP or PTD) into an organic TODGA-based solvent by increasing the TODGA concentration and/or that of nitric acid. The kinetics of re-extraction of Am(III) by a $0.2 \mathrm{M}$ TODGA solution was studied by increasing $\left[\mathrm{HNO}_{3}\right]_{a q}$ from $0.5 \mathrm{M}$ to $2 \mathrm{M}$ in the presence of $20 \mathrm{mM} \mathrm{SO}$-Ph-BTP. 
In Figure 9 are plotted the results for the re-extraction of ${ }^{241} \mathrm{Am}(\mathrm{III})$ in these conditions (the corresponding data are given in the Supporting Information). It is worth noting that the 3 plots exhibit a linear behavior when plotted with log-log axes. These results may be compared with those displayed in Table 4, which gives data for the effect of $\mathrm{HNO}_{3}$ in the absence of $\mathrm{SO}_{3}-\mathrm{Ph}-\mathrm{BTP}$.

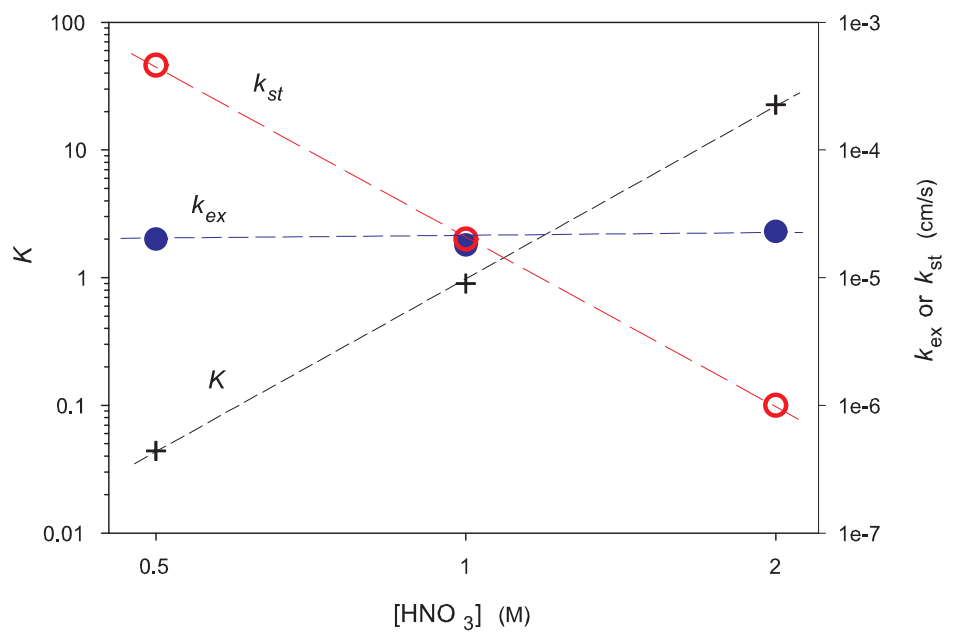

Figure 9: Re-extraction and stripping rates (right scale), and $K$ values (left scale), for ${ }^{241} \mathrm{Am}(\mathrm{III})$ between aqueous $20 \mathrm{mM} \mathrm{SO}$-Ph-BTP solutions of different $\mathrm{HNO}_{3}$ concentrations and organic $0.2 \mathrm{M}$ TODGA in TPH-O. $(+)=K ;(\bullet)=k_{e x} ;(\bigcirc)=k_{s t}$.

First, it is seen in Figure 9 that the partition coefficient, $K=k_{e x} / k_{s t}$, is dramatically enhanced (by $\sim 500$ times) when $\left[\mathrm{HNO}_{3}\right]_{a q}$ is varied from $0.5 \mathrm{M}$ to $2 \mathrm{M}$. This outcome is similar to that found in section 4.2 (Table 4 ), but the magnitude of the enhancement is much larger than in the absence of $\mathrm{SO}_{3}-\mathrm{Ph}-\mathrm{BTP}$. The interpretation of the effect of adding nitric acid is identical to that of section 4.2, invoking the Le Châtelier principle.

Then, it is noticed in Figure 9 that the extraction rate constant remains approximately constant vs. $\left[\mathrm{HNO}_{3}\right]$ (it was found to increase slightly in section 4.2). In contrast, the stripping rate constant decreases by more than two orders of magnitude when $\left[\mathrm{HNO}_{3}\right]_{a q}$ is increased from $0.5 \mathrm{M}$ to $2 \mathrm{M}$. This drop is therefore much more pronounced in the presence of $\mathrm{SO}_{3}-\mathrm{Ph}-\mathrm{BTP}$ than when it is absent (see Table 4, suggesting a decline by a factor of about 3 in this concentration range). The cause for this drop might be similar to that put forward 
in section 4.2, i.e. a more difficult release of nitrate and nitric acid from the complex at the interface.

In the industrial process, the kinetics of this extraction step will therefore be somewhat faster when using a more concentrated nitric acid solution, because the back-extraction rate constant $k_{s t}$ will then be much smaller ( $k_{e x}$ being approximately constant).

The $\mathrm{SO}_{3}$ - $\mathrm{Ph}$-BTP ligand (in which $\mathrm{SO}_{3}$ - $\mathrm{Ph}-\mathrm{BTP}$ denotes the tetravalent anionic form of the ligand) may become protonated in the presence of nitric acid (probably on a $\mathrm{N}$ donor atom of the central pyridine group ${ }^{60}$ ), with a first protonation constant, $\log _{10} K_{1} \simeq$ 0.5. ${ }^{61}$ The resulting $\mathrm{H} \cdot \mathrm{SO}_{3}$-Ph-BTP molecule, may not complex the Am(III) ions. ${ }^{61}$ As the concentration of nitric acid in the aqueous phase is increased, more ligand becomes (mono-)protonated, which decreases the amount of unprotonated ligand available to complex and strip Am(III). This process provides a qualitative interpretation of the variation of $K$. However, a simple calculation, using the value of $K_{1}$ and assuming thermodynamic ideality in the aqueous phase, shows that the drawdown of unprotonated ligand alone cannot explain the huge increase of $K$ and the big drop of $k_{s t}$ observed when the acid concentration is varied in this range. We note that a similar difficulty in interpreting the equilibrium data was encountered in the case of the uranyl cation in the presence of this same ligand. ${ }^{62}$ Further investigations would be needed to better understand the partitioning and kinetic behavior of this system.

\subsection{Addition of PTD}

As mentioned in the Introduction section, a drawback of the $\mathrm{SO}_{3}-\mathrm{Ph}-\mathrm{BTP}$ ligand is that it does not comply with the CHON principle suitable for complete incineration. On the contrary, the PTD ligand satisfies this condition. This molecule has proved to be a good alternative for stripping actinides from organic solutions. ${ }^{29,30}$ Its effect on the kinetics was studied in this work. 


\subsubsection{Effect of PTD concentration}

The results for the stripping and extraction rate constants, for $0.5 \mathrm{M} \mathrm{HNO}_{3}$ and $0.2 \mathrm{M}$ TODGA, are shown in Figures 10 (for $\mathrm{Eu}(\mathrm{III})$ ) and 11 (for $\mathrm{Am}(\mathrm{III})$ ), and collected in the Supporting Information. The values for the distribution ratio are given in the latter.

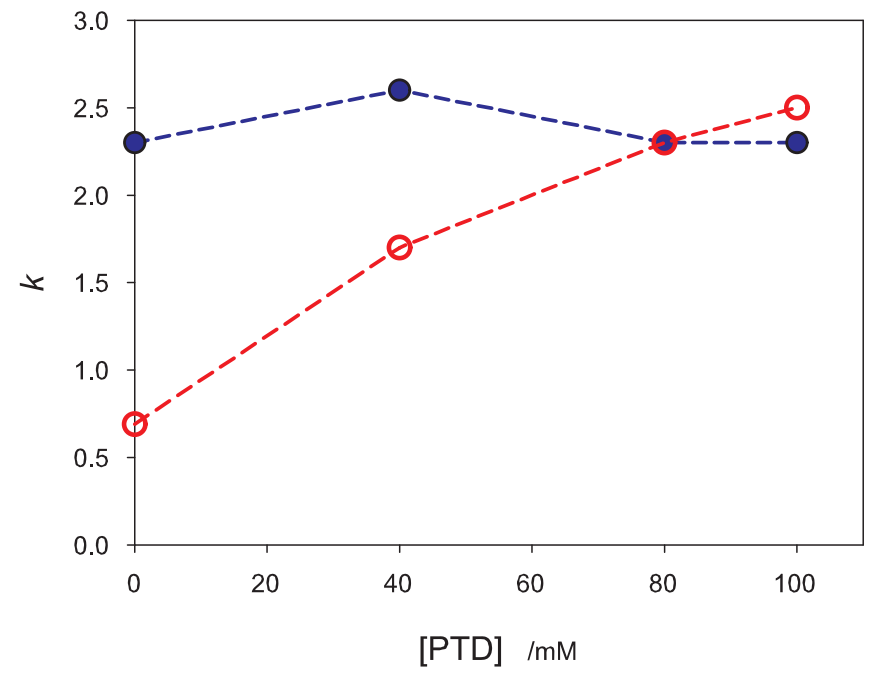

Figure 10: Extraction $(\bullet)$ and stripping $(\bigcirc)$ kinetic rate constants for ${ }^{152} \mathrm{Eu}(\mathrm{III})$ as a function of PTD concentration in aqueous phase in $0.5 \mathrm{M} \mathrm{HNO}_{3}$ solution, and organic phase: $0.2 \mathrm{M}$ TODGA in TPH-O. Plots in units of $10^{-3} \mathrm{~cm} \mathrm{~s}^{-1}$ for $k_{e x}$, and of $10^{-5} \mathrm{~cm} \mathrm{~s}^{-1}$ for $k_{s t}$. Dashed lines are guides for the eye.

It is seen in Table S10 that the aq/org distribution ratio, $1 / K$, rises with the concentration of PTD, as expected because PTD forms a complex with the metal ion in aqueous phase.

Figure 10 shows that the extraction rate constant for $\mathrm{Eu}(\mathrm{III})$ is nearly constant (within experimental uncertainty) with respect to the concentration of PTD. The stripping rate constant for $\mathrm{Eu}(\mathrm{III})$ increases significantly with [PTD]. In Figure 11 it is seen that the behavior of the extraction rate constant in the case of americium is quite different from that of europium, with a $k_{e x}$ for Am(III) that decreases sharply with the amount of added PTD. The extraction rate constant for $\mathrm{Eu}(\mathrm{III})$ is a few times larger than that for $\mathrm{Am}(\mathrm{III})$.

The rate constants for back-extraction, $k_{s t}$, increase notably with [PTD] for the two ions, with a 40-fold increase from 0 to $100 \mathrm{mM}$ of PTD in the case of Am(III). The stripping rate constant for $\mathrm{Eu}(\mathrm{III})$ is about 2 orders of magnitude smaller than that for Am(III) (but both 


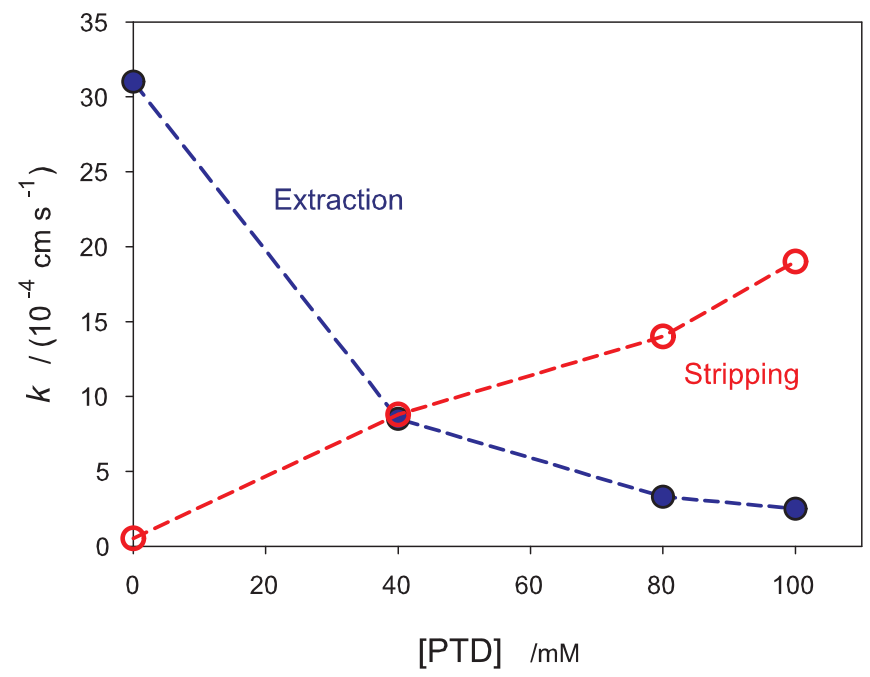

Figure 11: Extraction (•) and stripping (O) kinetic rate constants for ${ }^{241} \mathrm{Am}(\mathrm{III})$ as a function of PTD concentration in aqueous phase in $0.5 \mathrm{M} \mathrm{HNO}_{3}$ solution, and organic phase: $0.2 \mathrm{M}$ TODGA in TPH-O. Plots in units of $10^{-4} \mathrm{~cm} \mathrm{~s}^{-1}$. Dashed lines are guides for the eye.

increase with $[\mathrm{PTD}])$.

The fact that the rate constant for back-extraction increases nearly linearly with [PTD] suggests, similarly to the case of $\mathrm{SO}_{3}$-Ph-BTP, that PTD captures the ion at the interface with a probability that is proportional to [PTD], and takes it to the aqueous phase. One may write, $k_{s t}=k_{s t}^{(0)}+\lambda[\mathrm{PTD}]$, in which $k_{s t}^{0}$ is the rate constant in the absence of PTD and $\lambda$ is a constant.

To interpret the steep variation of $k_{e x}$ in the case of Am(III) it was examined whether the rate constant could be expressed as $k_{e x}=k_{e x}^{(0)} \alpha_{0}$, in which $\alpha_{0}$ is the fraction of free $\mathrm{Am}^{3+}$ ion, and $k_{e x}^{(0)}$ is the extraction rate constant in the absence of PTD. Moreover, it was assumed that the complexed americium is predominantly in the form of one complex, $\operatorname{Am}(\mathrm{PTD})_{n}$ (with $n$ a constant integer). A mass action law was used for this complex, and different values of $n(n=1,2$ and 3$)$ were tested. A plot of $1 / k_{e x}$ as a function of [PTD $]^{2}$ approximately gave a straight line on the whole PTD concentration range (not shown), thus suggesting a stoichiometry of 2 for the main complex $\left(\mathrm{Am}(\mathrm{PTD})_{2}\right)$. Values of $n=1$ or 3 did not give a straight line. The present result is in keeping with the speciation found in 
ref. 30 (see Figure 5 of this reference) in which the predominant 1-2 complex was identified in the case of $\mathrm{Cm}(\mathrm{III})$, whose behavior is very close to that of $\mathrm{Am}(\mathrm{III}) \cdot{ }^{29,30}$ The fact that $k_{e x}$ is constant when PTD is added to a $\mathrm{Eu}(\mathrm{III})$ solution might be related to the much lower complexation constant for this metal ion. ${ }^{30}$

As in the case of $\mathrm{SO}_{3}-\mathrm{Ph}-\mathrm{BTP}$, it is interesting to look at the $\mathrm{Am} / \mathrm{Eu}$ equilibrium and kinetic separation factors, $\mathrm{SF}$ and $\mathrm{SF}_{\text {kin }}$ (eq 10), respectively. They are plotted in Figure 12 as a function of the PTD concentration. As previously observed for $\mathrm{SO}_{3}-\mathrm{Ph}-\mathrm{BTP}$, both separation factors are strongly enhanced by addition of ligand.

Therefore, here too, the separation of $\mathrm{Am}$ (III) from $\mathrm{Eu}(\mathrm{III})$ by stripping is greatly enhanced by the aqueous ligand (PTD), both thermodynamically and kinetically. This should be quite favorable for An/Ln separation with the CHON-compliant stripping agent PTD, using short-time phase contacting extractors in SANEX and GANEX processes.

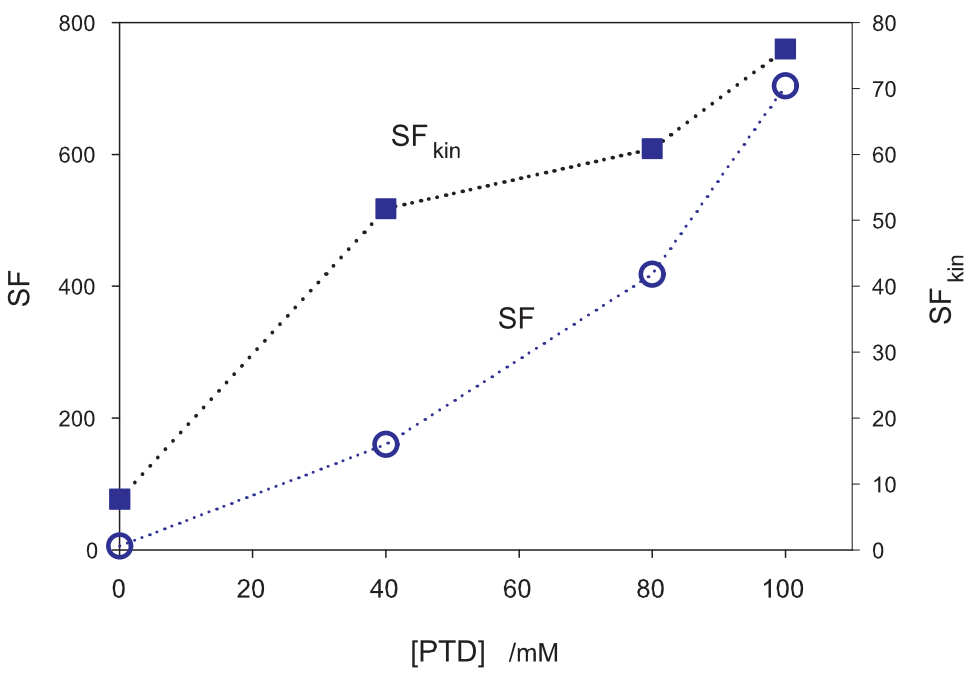

Figure 12: $\mathrm{Am} / \mathrm{Eu}$ equilibrium (SF, left scale) and kinetic $\left(\mathrm{SF}_{k i n}\right.$, right scale) separation factors in the case of PTD.

\subsubsection{Effect of $\mathrm{HNO}_{3}$ concentration (in the presence of PTD)}

As done in section 5.1.2 in the case of $\mathrm{SO}_{3}$-Ph-BTP, the influence of the $\mathrm{HNO}_{3}$ concentration was studied in the case of Am(III), in conditions suitable for the stripping of actinide 
ions, ${ }^{29,30,63}$ namely with $[\mathrm{PTD}]=80 \mathrm{mM}$ and $0.2 \mathrm{M}$ TODGA, for 2 values of aqueous nitric acid concentration, $\left[\mathrm{HNO}_{3}\right]=0.1 \mathrm{M}$ and $0.5 \mathrm{M}$.

The results are collected in Table 5. They may be compared with those of sections 4.2 (absence of hydrophilic ligand) and 5.1.2 (use of $\mathrm{SO}_{3}$-Ph-BTP ligand).

Table 5: Distribution ratio, $K$, and kinetic rate constants for ${ }^{241} \mathrm{Am}(\mathrm{III})$ at the interface between an organic phase of $0.2 \mathrm{M}$ TODGA in TPH-O and aqueous solutions of various $\mathrm{HNO}_{3}$ concentrations with $[\mathrm{PTD}]=80 \mathrm{mM}$.

\begin{tabular}{llll}
\hline$\left[\mathrm{HNO}_{3}\right]$ & $K$ & $k_{e x}\left(\mathrm{~cm} \mathrm{~s}^{-1}\right)$ & $k_{s t}\left(\mathrm{~cm} \mathrm{~s}^{-1}\right)$ \\
\hline $0.1 \mathrm{M}$ & $1.05 \times 10^{-3}$ & $1.9 \times 10^{-7}$ & $1.8 \times 10^{-4}$ \\
$0.5 \mathrm{M}$ & 0.237 & $4.1 \times 10^{-4}$ & $17 \times 10^{-4}$ \\
\hline
\end{tabular}

In this table we see that $K$ is strongly enhanced (by a factor of more than 200) when $\left[\mathrm{HNO}_{3}\right]$ is increased from $0.1 \mathrm{M}$ to $0.5 \mathrm{M}$. This behavior is consistent with a previous study ${ }^{30}$ in which decomplexation of the metal cation was observed when increasing the acid concentration, and it is similar to what was found in sections 4.2 and 5.1.2. As in these sections, the Le Châtelier principle may be invoked to explain the increase of the distribution ration with the acid concentration.

At the same time the extraction kinetics is dramatically enhanced by more than 3 orders of magnitude, and the stripping kinetics is enhanced by about 10 times. The huge enhancement of $k_{e x}$ contrasts strongly with the mild rise observed in the absence of aqueous ligand, and the flat behavior found when using $\mathrm{SO}_{3}-\mathrm{Ph}-\mathrm{BTP}$. The softer rise of $k_{s t}$ also contrasts with the drops found without ligand and in the presence of $\mathrm{SO}_{3}-\mathrm{Ph}-\mathrm{BTP}$. The increase observed for $k_{e x}$ may be explained along the same lines as those put forward in sections 4.2 and 5.1.2. The origin of the acceleration of the stripping step is unknown at this stage. The aqueous ligand PTD therefore behaves quite differently than the other ligand $\mathrm{SO}_{3}-\mathrm{Ph}-\mathrm{BTP}$.

The results of this section suggest the use of concentrated nitric acid solutions in the process at the industrial scale, in order to accelerate the re-extraction of Am(III). 


\section{Selective extraction with $\mathrm{CyMe}_{4}-\mathrm{BTBP}$ (+ TODGA) in 1-octanol}

The combination of $10 \mathrm{mM} \mathrm{CyMe} 4$-BTBP with $5 \mathrm{mM}$ TODGA extractant, acting as a phase-transfer catalyst, in 1-octanol has been retained for actinide selective extraction in the one-cycle SANEX (1c-SANEX) process. ${ }^{64,65}$

The kinetics of extraction of $\mathrm{Eu}(\mathrm{III})$ and $\mathrm{Am}(\mathrm{III})$ were investigated. The transfer was made from an aqueous $3 \mathrm{M} \mathrm{HNO}_{3}$ solution into organic solutions of $\mathrm{CyMe}_{4}-\mathrm{BTBP}+\mathrm{TODGA}$ in 1-octanol. The phase-transfer catalyst, TODGA, was added in order to accelerate the extraction kinetics.

The results are shown in Table 6. The actinide-selective extractant $\mathrm{CyMe}_{4}-\mathrm{BTBP}$ at $10 \mathrm{mM}$ yielded a high separation factor, $\mathrm{SF}(\mathrm{Am} / \mathrm{Eu})=K(\mathrm{Am}) / K(\mathrm{Eu})$, of about 105 when it was used alone, but a very slow extraction rate, with $k_{e x}$ on the order of $10^{-7}-10^{-6} \mathrm{~cm}$ $\mathrm{s}^{-1}$. Very slow extraction kinetics were obtained for $\mathrm{Eu}(\mathrm{III})$ and $\mathrm{Am}(\mathrm{III})$. The rate constant for $\operatorname{Am}(\mathrm{III})\left(k_{e x}(\mathrm{Am})=7.2 \times 10^{-6} \mathrm{~cm} \mathrm{~s}^{-1}\right)$ was nevertheless 24 times larger than that for $\mathrm{Eu}(\mathrm{III})$.

Table 6: Effect of the phase-transfer catalyst TODGA on the kinetics of extraction by $\mathrm{CyMe}_{4}$-BTBP. Aqueous phase: $3 \mathrm{M} \mathrm{HNO}_{3}$ solution spiked with ${ }^{152} \mathrm{Eu}$ or ${ }^{241} \mathrm{Am}$. Organic phase: $5 \mathrm{mM}$ or $10 \mathrm{mM} \mathrm{CyMe} \mathrm{m}_{4}$ BTBP in 1-octanol, with or without $5 \mathrm{mM}$ TODGA.

\begin{tabular}{lrrllcc}
\hline$\left[\mathrm{CyMe}_{4}-\mathrm{BTBP}\right]$ & {$[\mathrm{TODGA}]$} & $K(\mathrm{Eu})$ & $K(\mathrm{Am})$ & $\mathrm{SF}(\mathrm{Am} / \mathrm{Eu})$ & $\begin{array}{c}k_{e x}(\mathrm{Eu}) \\
/\left(10^{-5} \mathrm{~cm} \mathrm{~s}^{-1}\right)\end{array}$ & $\begin{array}{c}k_{e x}(\mathrm{Am}) \\
/\left(10^{-5} \mathrm{~cm} \mathrm{~s}^{-1}\right)\end{array}$ \\
\hline $10 \mathrm{mM}$ & 0 & 0.281 & 29.3 & 105 & 0.0302 & 0.720 \\
0 & $5 \mathrm{mM}$ & 0.394 & 0.142 & 0.360 & 10.5 & 29.4 \\
Sum of previous entries & & 0.675 & 29.4 & & 10.5 & 30.1 \\
$10 \mathrm{mM}$ & $5 \mathrm{mM}$ & 0.980 & 33.1 & 33.8 & 8.76 & 6.19 \\
\hline $5 \mathrm{mM}$ & $5 \mathrm{mM}$ & 0.593 & 9.07 & 15.3 & 8.12 & 5.72 \\
\hline
\end{tabular}

Fast extraction kinetics have been found in section 4.1 for TODGA alone in TPH-O. Here, even with a small amount of TODGA $(5 \mathrm{mM})$, a rather high extraction rate constant was obtained for $\mathrm{Am}(\mathrm{III}): k_{e x}(\mathrm{Am}) \sim 2.9 \times 10^{-4} \mathrm{~cm} \mathrm{~s}^{-1}$, which is 2.8 times that for $\mathrm{Eu}(\mathrm{III})$ : $k_{e x}(\mathrm{Eu}) \sim 1.1 \times 10^{-4} \mathrm{~cm} \mathrm{~s}^{-1}$ (see Table 6). However, the distribution ratios $K(\mathrm{Eu})$ and 
$K(\mathrm{Am})$ were low.

A slight synergistic effect is observed in Table 6, where the value of the distribution ratio $K$ for the mixture $10 \mathrm{mM} \mathrm{CyMe}_{4}$-BTBP $+5 \mathrm{mM}$ TODGA is observed to be larger than the sum of the individual $K$ values for the two extractants, for both $\mathrm{Eu}$ (III) $(0.98>0.28+0.39=$ $0.67)$ and $\mathrm{Am}(\mathrm{III})(33.1>29.3+0.14=29.4)$ extraction. Nonetheless, the separation factor is considerably reduced to $\mathrm{SF}(\mathrm{Am} / \mathrm{Eu}) \sim 34$ as compared to that with $\mathrm{CyMe}_{4}$ - $\mathrm{BTBP}$ alone $(\mathrm{SF}=105)$.

As regards the kinetics, it is clearly observed that the extraction kinetics of $\mathrm{Eu}(\mathrm{III})$ and Am(III) are greatly accelerated when the extractants are combined as compared to the case of $\mathrm{CyMe}_{4}-\mathrm{BTBP}$ alone: the rate constants $k_{e x}(\mathrm{Eu})$ and $k_{e x}(\mathrm{Am})$ are about 290 and 9 times higher, respectively (passing from $0.0302 \times 10^{-5} \mathrm{~cm} \mathrm{~s}^{-1}$ to $8.76 \times 10^{-5} \mathrm{~cm} \mathrm{~s}^{-1}$ in the case of $\mathrm{Eu}(\mathrm{III})$, and from $0.720 \times 10^{-5} \mathrm{~cm} \mathrm{~s}^{-1}$ to $6.19 \times 10^{-5} \mathrm{~cm} \mathrm{~s}^{-1}$ in that of $\left.\mathrm{Am}(\mathrm{III})\right)$. However, the extraction rate constant $k_{e x}$ is of the order of a few $10^{-5} \mathrm{~cm} \mathrm{~s}^{-1}$, which is a moderate value.

It is seen on the last line of Table 6 that, when $\left[\mathrm{CyMe}_{4}\right.$-BTBP] is lowered from $10 \mathrm{mM}$ to $5 \mathrm{mM}$ in the presence of $5 \mathrm{mM}$ TODGA catalyst, the extraction kinetics of $\mathrm{Eu}(\mathrm{III})$ and Am(III) remain nearly unchanged (within the experimental uncertainty), but the distribution ratios are significantly lowered. This observation is consistent with the expectation that the kinetics are controlled by TODGA, not by $\mathrm{CyMe}_{4}$-BTBP. However, it is also seen in Table 6 that the extraction rate constants for the mixture are lower than with TODGA alone (8.8 $<10.5$ for $k_{e x}(\mathrm{Eu})$, and above all $6.2 \ll 29.4$ for $\left.k_{e x}(\mathrm{Am})\right)$.

As regards the 1c-SANEX process, it seems that the mixture $10 \mathrm{mM} \mathrm{CyMe}{ }_{4}-\mathrm{BTBP}+5$ mM TODGA is a good formulation that preserves a rather high Am/Eu separation factor $(\mathrm{SF} \sim 34)$ and accelerates the extraction as compared to pure $\mathrm{CyMe}_{4}-\mathrm{BTBP}$. However, the extraction kinetics of $\mathrm{Eu}(\mathrm{III})$ and $\mathrm{Am}(\mathrm{III})$ are comparable $\left(k_{e x}(\mathrm{Am})\right.$ even seems to be a little smaller than $\left.k_{e x}(\mathrm{Eu})\right)$. This point may reduce the interest of using a centrifugal extractor for the separation of $\mathrm{Am}(\mathrm{III})$ from $\mathrm{Eu}(\mathrm{III})$ in the case of $\mathrm{CyMe}_{4}-\mathrm{BTBP}$. 


\section{$7 \quad$ Effect of temperature}

The influence of temperature on the kinetics of extraction was examined at temperatures of $22^{\circ} \mathrm{C}$ and $35^{\circ} \mathrm{C}$ (in a thermostated chamber). The results for the extraction of $\mathrm{Eu}(\mathrm{III})$ and Am(III) by $0.2 \mathrm{M}$ TODGA in TPH-O, and by $10 \mathrm{mM} \mathrm{CyMe}-\mathrm{BTBP}+5 \mathrm{mM}$ TODGA in 1-octanol, are collected in Tables 7 and 8, respectively.

Table 7: Influence of the temperature on the extraction kinetic rate constant for ${ }^{152} \mathrm{Eu}$ and ${ }^{241} \mathrm{Am}$. Aqueous phase: $0.5 \mathrm{M} \mathrm{HNO}_{3}+20 \mathrm{mM} \mathrm{SO}_{3}$-Ph-BTP. Organic phase: $0.2 \mathrm{M}$ TODGA in TPH-O pre-equilibrated with the aqueous phase.

\begin{tabular}{lclcc}
\hline Ion & $T$ & $K$ & $k_{e x}\left(\mathrm{~cm} \mathrm{~s}^{-1}\right)$ & $k_{s t}\left(\mathrm{~cm} \mathrm{~s}^{-1}\right)$ \\
\hline${ }^{152} \mathrm{Eu}(\mathrm{III})$ & $22^{\circ} \mathrm{C}$ & 30.6 & $2.2 \times 10^{-4}$ & $7.3 \times 10^{-6}$ \\
& $35^{\circ} \mathrm{C}$ & 11.6 & $2.5 \times 10^{-4}$ & $22 \times 10^{-6}$ \\
${ }^{241} \mathrm{Am}$ & $22^{\circ} \mathrm{C}$ & 0.0437 & $2.0 \times 10^{-5}$ & $4.6 \times 10^{-4}$ \\
& $35^{\circ} \mathrm{C}$ & 0.0187 & $2.2 \times 10^{-5}$ & $12 \times 10^{-4}$ \\
\hline
\end{tabular}

Table 8: Influence of the temperature on the extraction kinetic rate constant for ${ }^{152} \mathrm{Eu}$ and ${ }^{241} \mathrm{Am}$. Aqueous phase: $3 \mathrm{M} \mathrm{HNO}_{3}$. Organic phase: $10 \mathrm{mM} \mathrm{CyMe}_{4}-\mathrm{BTBP}+5 \mathrm{mM}$ TODGA in 1-octanol (pre-equilibrated with the aqueous phase).

\begin{tabular}{lrlll}
\hline Ion & $T$ & $K$ & $k_{e x}\left(\mathrm{~cm} \mathrm{~s}^{-1}\right)$ & $k_{s t}\left(\mathrm{~cm} \mathrm{~s}^{-1}\right)$ \\
\hline${ }^{152} \mathrm{Eu}(\mathrm{III})$ & $22^{\circ} \mathrm{C}$ & 0.819 & $8.8 \times 10^{-5}$ & $9.0 \times 10^{-5}$ \\
& $35^{\circ} \mathrm{C}$ & 0.674 & $6.1 \times 10^{-5}$ & $9.1 \times 10^{-5}$ \\
${ }^{241} \mathrm{Am}(\mathrm{III})$ & $22^{\circ} \mathrm{C}$ & 31.3 & $6.2 \times 10^{-5}$ & $2.0 \times 10^{-6}$ \\
& $35^{\circ} \mathrm{C}$ & 22.4 & $5.6 \times 10^{-5}$ & $2.5 \times 10^{-6}$ \\
\hline
\end{tabular}

An increase in the temperature from $22^{\circ} \mathrm{C}$ to $35^{\circ} \mathrm{C}$ lowers the distribution ratios $K$ of $\mathrm{Eu}$ (III) and $\mathrm{Am}$ (III) by a factor of $\sim 2$ or 3 in the first case, and by about $30 \%$ in the second, indicating that the extraction reaction for both cations is exothermic. In other words, the activation energy of $K$ is negative, as is often the case in extraction systems. This peculiarity has been shown to have potentially a strong influence on the apparent activation energy of the overall extraction process, and may lead to incorrect interpretations about the nature of the extraction regime (diffusion vs. kinetic control). ${ }^{34}$

The values of the activation energies calculated using the $K$ results at the two temperatures of $22^{\circ} \mathrm{C}$ and $35^{\circ} \mathrm{C}$ are: $-24.5 \mathrm{~kJ} \mathrm{~mol}^{-1}$ and $-21.4 \mathrm{~kJ} \mathrm{~mol}^{-1}$ for the data of Table 7 in 
the case of $\mathrm{Eu}(\mathrm{III})$ and $\mathrm{Am}(\mathrm{III})$, respectively, and of $-4.9 \mathrm{~kJ} \mathrm{~mol}^{-1}$ and $-8.4 \mathrm{~kJ} \mathrm{~mol}^{-1}$ for the data of Table 8 for $\mathrm{Eu}(\mathrm{III})$ and $\mathrm{Am}(\mathrm{III})$, respectively.

The extraction kinetics of $\mathrm{Eu}(\mathrm{III})$ might be slightly accelerated by an increase of $T$ from $22^{\circ} \mathrm{C}$ to $35^{\circ} \mathrm{C}$ in Table 7 , and they seem to be moderately decelerated in Table 8 . In contrast, they do not exhibit a clear trend in this temperature range in the case of Am(III). Although a small reduction is observed in the rate constants $k_{e x}(\mathrm{Am})$, this variation is not significant in view of an uncertainty of the order of $10 \%$ or $20 \%$ (see section 3 ).

\section{Conclusion}

In this study several improvements have been brought to the RMC technique. Two types of Millipore membranes (hydrophilic vs. hydrophobic) have been used to contain the aqueous or the organic phase, respectively. The membranes were glued on the base of the plastic cylinder by using liquid Kapton. The lower part of the cylinder itself was covered with Kapton in order to isolate it from the solution in which it was immersed.

The results obtained in section 3 by performing extraction and stripping kinetic experiments were in agreement within experimental uncertainty. The values of the diffusion coefficients of the solutes $\mathrm{Eu}(\mathrm{III})$ and $\mathrm{Am}(\mathrm{III})$ in the phases, which are required in the treatment of the kinetic data, were measured using the RMC. The validity of the procedure was confirmed by also measuring separately a few diffusion coefficients by using the closed capillary technique. Measuring the D's with the RMC makes this step much easier and shorter in time than with the capillary technique.

Extraction and stripping of $\mathrm{Eu}(\mathrm{III})$ and $\mathrm{Am}(\mathrm{III})$ were studied for various concentrations of nitric acid and TODGA, in mixtures of $\mathrm{CyMe}_{4}-\mathrm{BTBP}$ with TODGA, and in the presence of the aqueous ligands $\mathrm{SO}_{3}$-Ph-BTP and PTD. It was somewhat striking to find that TODGA is not surface active at the interface between nitric acid and TPH-O, which is in contrast with the case of TODGA in $n$-dodecane. 
The kinetic data obtained in this work will be used as input parameters in simulation codes (such as, e.g., PAREX, developed at $\mathrm{CEA}^{22,23}$ ) for a modeling of separation processes carried out in extractors (e.g., centrifugal) that operate with a short contact time between the phases.

The experimental results, obtained with TODGA and the two aqueous stripping ligands, show that faster transfer kinetics are associated with higher partitioning for Am(III) over $\mathrm{Eu}(\mathrm{III})$. This favorable outcome bodes well for future efficient actinide/lanthanide separation in the nuclear reprocessing industry.

\section{Acknowledgements}

This work was supported by grants from the European Commission within the Euratom project GENIORS (Grant Agreement number: 755171), and from the Italian Ministry of Instruction (University and Research programme, COMP-HUB initiative, Departments of Excellence Programme). Comments and advice from Giuseppe Modolo, Robin Taylor and Andreas Geist are gratefully acknowledged. We thank Udo Müllich and Andreas Geist for providing the $\mathrm{SO}_{3}$-Ph-BTP and $\mathrm{CyMe}_{4}$-BTBP compounds, and Laurence Berthon for some useful data.

Constructive comments from an unknown reviewer are acknowledged.

\section{ASSOCIATED CONTENT}

Supporting Information

This information is available free of charge via the Internet at http://pubs.acs.org/.

Details on the practical use of the RMC; Densities, and dynamic and kinematic viscosities of solutions; Diffusion coefficients; Distribution ratios and kinetic rate constants. 


\section{References}

(1) Klass, L.; Wilden, A.; Kreft, F.; Wagner, C.; Geist, A.; Panak, P. J.; HerdzikKoniecko, I.; Narbutt, J.; Modolo, G. Evaluation of the Hydrophilic Complexant N,N,N',N'-tetraethyldiglycolamide (TEDGA) and its Methyl-substituted Analogues in the Selective Am(III) Separation. Solvent Extr. Ion Exch. 2019, 37, 297-312.

(2) Joly, P.; Boo, E. ROADMAP: Actinide separation processes 2015; 2015; Available at http://www.sacsess.eu/Docs/SACSESS.PDF.

(3) Sanders, M. C.; Sanders, C. E. A world's dilemma 'upon which the sun never sets'-The nuclear waste management strategy (part I): Western European Nation States and the United States of America. Prog. Nucl. Energy 2016, 90, 69-97.

(4) Sanders, M. C.; Sanders, C. E. A world's dilemma 'upon which the sun never sets': The nuclear waste management strategy (part II): Russia, Asia and the Southern Hemisphere. Prog. Nucl. Energy 2019, 110, 148-169.

(5) Chen, J.; He, X.; Wang, J. Nuclear fuel cycle-oriented actinides separation in China. Radiochimica Acta 2014, 102, 41-51.

(6) Chen, Y.; Martin, G.; Chabert, C.; Eschbach, R.; He, H.; an Ye, G. Prospects in China for nuclear development up to 2050. Prog. Nucl. Energy 2018, 103, $81-90$.

(7) Geist, A.; Taylor, R.; Ekberg, C.; Guilbaud, P.; Modolo, G.; Bourg, S. The SACSESS Hydrometallurgy Domain - An Overview. Procedia Chem. 2016, 21, 218 - 222.

(8) Bourg, S.; Geist, A.; Adnet, J.; Rhodes, C.; Hanson, B. GENIORS, a new European project addressing Gen IV integrated oxide fuels recycling strategies. Proceedings of GLOBAL 2017. 2017; pp 24-29.

(9) Madic, C.; Hudson, M. High-level liquid waste partitioning by means of completely incinerable extractants. European Commission; 1998; Available at 
https://op.europa.eu/en/publication-detail/-/publication/c16b289a-6637-44c0-a3bd$9 \mathrm{c} 2 \mathrm{db} 414 \mathrm{f} 800$.

(10) Modolo, G.; Wilden, A.; Kaufholz, P.; Bosbach, D.; Geist, A. Development and demonstration of innovative partitioning processes (i-SANEX and 1-cycle SANEX) for actinide partitioning. Prog. Nucl. Energ. 2014, 72, 107-114.

(11) Modolo, G.; Geist, A.; Miguirditchian, M. In Reprocessing and recycling of spent nuclear fuel; Taylor, R., Ed.; Elsevier, 2015; pp 245-287.

(12) Taylor, R.; Carrott, M.; Galan, H.; Geist, A.; Hérès, X.; Maher, C.; Mason, C.; Malmbeck, R.; Miguirditchian, M.; Modolo, G.; Rhodes, C.; Sarsfield, M.; Wilden, A. The EURO-GANEX Process: Current Status of Flowsheet Development and Process Safety Studies. Procedia Chem. 2016, 21, 524-529.

(13) Malmbeck, R.; Magnusson, D.; Bourg, S.; Carrott, M.; Geist, A.; Hérès, X.; Miguirditchian, M.; Modolo, G.; Müllich, U.; Sorel, C.; Taylor, R.; Wilden, A. Homogenous recycling of transuranium elements from irradiated fast reactor fuel by the EUROGANEX solvent extraction process. Radiochim. Acta 2019, 107, 917-929.

(14) Lanham, W.; Runion, T. PUREX process for plutonium and uranium recovery; 1949; Available at https://www.osti.gov/servlets/purl/4165457.

(15) Hill, C.; Berthon, L.; Guillaneux, D.; Dancausse, J.; Madic, C. SANEX-BTP process development: from bench to hot test demonstration. Proceedings of Atalante 2004 conference. 2004.

(16) Salvatores, M. Nuclear fuel cycle strategies including Partitioning and Transmutation. Nucl. Eng. Des. 2005, 235, $805-816$.

(17) Sasaki, Y.; Sugo, Y.; Suzuki, S.; Tachimori, S. The novel extractants, diglycolamides, 
for the extraction of lanthanides and actinides in $\mathrm{HNO}_{3}$-n-dodecane system. Solvent Extr. Ion Exch. 2001, 19, 91-103.

(18) Wilden, A.; Modolo, G.; Sypula, M.; Geist, A.; Magnusson, D. The recovery of An(III) in an innovative-SANEX process using a TODGA-based solvent and selective stripping with a hydrophilic BTP. Procedia Chem. 2012, 7, 418-424.

(19) Wilden, A.; Schreinemachers, C.; Sypula, M.; Modolo, G. Direct Selective Extraction of Actinides(III) from PUREX Raffinate using a Mixture of $\mathrm{CyMe}_{4} \mathrm{BTBP}$ and TODGA as 1-cycle SANEX Solvent. Solvent Extr. Ion Exch. 2011, 29, 190-212.

(20) Tachimori, S.; Sasaki, Y.; Suzuki, S. Modification of TODGA- $n$-dodecane solvent with a monoamide for high loading of lanthanides(III) and actinides(III). Solvent Extr. Ion Exch. 2002, 20, 687-699.

(21) Geist, A.; Modolo, G. TODGA process development: an improved solvent formulation. Proceedings of Global 2009. 2009.

(22) Dinh, B.; Montuir, M.; Baron, P. PAREX, A numerical Code for process design and integration. Proceedings of GLOBAL 2013: International Nuclear Fuel Cycle ConferenceNuclear Energy at a Crossroads. 2013.

(23) Bisson, J.; Dinh, B.; Huron, P.; Huel, C. PAREX, A Numerical Code in the Service of La Hague Plant Operations. Procedia Chem. 2016, 21, 117 - 124.

(24) Zhu, W.-B.; Ye, G.-A.; Li, F.-F.; Li, H.-R. Kinetics and mechanism of Am(III) extraction with TODGA. J. Radioanal. Nucl. Chem. 2013, 298, 1749-1755.

(25) Bromley, M. A.; Boxall, C. A Study of Cerium Extraction Kinetics by TODGA in Acidified and Non-Acidified Organic Solvent Phases in the Context of Fission Product Management. Prog. Nucl. Sci. Technol. 2018, 5, 70-73. 
(26) Sypula, M.; Ouadi, A.; Gaillard, C.; Billard, I. Kinetics of metal extraction in ionic liquids: $\mathrm{Eu}^{3+} / \mathrm{HNO}_{3} / / \mathrm{TODGA} /\left[\mathrm{C}_{1} \mathrm{C}_{4} \mathrm{im}\right]\left[\mathrm{Tf}_{2} \mathrm{~N}\right]$ as a case study. $R S C \operatorname{Adv} \mathbf{2 0 1 3}$, 3, 10736-10744.

(27) Simonin, J. P.; Weill, J. Rotating membrane cell technique for the study of liquid/liquid extraction kinetics. Solvent Extr. Ion Exch. 1998, 16, 1493-1514.

(28) Geist, A.; Müllich, U.; Magnusson, D.; Kaden, P.; Modolo, G.; Wilden, A.; Zevaco, T. Actinide(III)/Lanthanide(III) Separation Via Selective Aqueous Complexation of Actinides(III) using a Hydrophilic 2,6-Bis(1,2,4-Triazin-3-Yl)-Pyridine in Nitric Acid. Solvent Extr. Ion Exch. 2012, 30, 433-444.

(29) Macerata, E.; Mossini, E.; Scaravaggi, S.; Mariani, M.; Mele, A.; Panzeri, W.; Boubals, N.; Berthon, L.; Charbonnel, M.-C.; Sansone, F.; Arduini, A.; Casnati, A. Hydrophilic Clicked 2,6-Bis-triazolyl-pyridines Endowed with High Actinide Selectivity and Radiochemical Stability: Toward a Closed Nuclear Fuel Cycle. J. Am. Chem. Soc. 2016, 138, 7232-7235.

(30) Wagner, C.; Mossini, E.; Macerata, E.; Mariani, M.; Arduini, A.; Casnati, A.; Geist, A.; Panak, P. J. Time-resolved laser fluorescence spectroscopy study of the coordination chemistry of a hydrophilic CHON [1, 2, 3-triazol-4-yl] pyridine ligand with Cm(III) and Eu(III). Inorg. Chem. 2017, 56, 2135-2144.

(31) Durand-Vidal, S.; Simonin, J.-P.; Turq, P. Electrolytes at interfaces; Kluwer Academic Publishers, Dordrecht-Boston-London, 2000.

(32) Tarasov, V. V.; Kizim, N. F.; Yagodin, G. A. Kinetics of extraction and re-extraction during a brief contact between phases. Russ. J. Phys. Chem. 1971, 45, 1425-1428.

(33) Albery, W. J.; Burke, J. F.; Leffler, E. B.; Hadgraft, J. Interfacial transfer studied with a rotating diffusion cell. J. Chem. Soc. Faraday Trans. 1976, 72, 1618-1626. 
(34) Simonin, J. P.; Perrigaud, L.; Perrigaud, K.; Vu, T. H. Kinetics of liquid/liquid extraction of europium(III) cation by two malonic diamides. Solvent Extr. Ion Exch. 2014, 32, 365-377.

(35) Danesi, P. R. Solvent Extraction Principles and Practice, Second Edition; Marcel Dekker, New York-Basel, 2004; p 226.

(36) Ciceri, D.; Perera, J. M.; Stevens, G. W. The use of microfluidic devices in solvent extraction. J. Chem. Technol. Biotechnol. 2014, 89, 771-786.

(37) Corne, F.; Lélias, A.; Magnaldo, A.; Sorel, C.; Di Miceli Raimondi, N.; Prat, L. Experimental methodology for kinetic acquisitions using high velocities in a microfluidic device. Chem. Eng. Technol. 2019, 42, 2223-2230.

(38) Launiere, C. A.; Gelis, A. V. High Precision Droplet-Based Microfluidic Determination of Americium(III) and Lanthanide(III) Solvent Extraction Separation Kinetics. Ind. Eng. Chem. Res. 2016, 55, 2272-2276.

(39) Vansteene, A.; Jasmin, J.-P.; Cote, G.; Mariet, C. Segmented Microflows as a Tool for Optimization of Mass Transfer in Liquid- Liquid Extraction: Application at the Extraction of Europium(III) by a Malonamide. Ind. Eng. Chem. Res. 2018, 57, 1157211582.

(40) Sasaki, Y.; Sugo, Y.; Tachimori, S. Actinide separation with a novel tridentate ligand, diglycolic amide for application to partitioning process. Proceedings of ATALANTE 2000. 2000; pp 02-07.

(41) Hanson, C.; Hughes, M. A.; Marsland, J. G. Mass transfer with chemical reaction in liquid-liquid systems. Proceedings of ISEC'74. 1974.

(42) Hanson, C. In Hydrometallurgical Process Fundamentals; Bautista, R. G., Ed.; Springer US: Boston, MA, 1984; pp 315-325. 
(43) Rod, V. Kinetics of Metal Extraction by Chelate Formation: Part I: Mass Transfer with a Fast Reversible Chemical Reaction and Product Extraction. Chem. Eng. J. 1980, 20, $131-137$.

(44) Levich, V. G. Physicochemical Hydrodynamics; Englewood Cliffs, N.J.,Prentice-Hall, 1962.

(45) Simonin, J.-P.; Hendrawan, H. Effect of a salt on the kinetics of solute transfer at a free liquid/liquid interface. J. Phys. Chem. B 2000, 104, 7163-7170.

(46) Leoncini, A.; Huskens, J.; Verboom, W. Preparation of Diglycolamides via SchottenBaumann Approach and Direct Amidation of Esters. Synlett 2016, 27, 2463-2466.

(47) Simonin, J. P.; Mills, R.; Perera, A.; Turq, P.; Tallet, F. Closed capillary method for the diffusion of biological macromolecules. J. Solution Chem. 1986, 15, 1015-1030.

(48) Simonin, J.-P.; Ramos, J. M.; Torres-Arenas, J. Diffusion coupling in multiply associating electrolyte solutions. J. Mol. Liq. 2016, 215, 69-76.

(49) Price, W. S. NMR Studies of Translational Motion: Principles and Applications; Cambridge Molecular Science; Cambridge University Press, 2009.

(50) Sasaki, Y.; Rapold, P.; Arisaka, M.; Hirata, M.; Kimura, T.; Hill, C.; Cote, G. An Additional Insight into the Correlation between the Distribution Ratios and the Aqueous Acidity of the TODGA System. Solvent Extr. Ion Exch. 2007, 25, 187-204.

(51) Ansari, S.; Pathak, P.; Husain, M.; Prasad, A.; Parmar, V.; Manchanda, V. Extraction of actinides using N,N,N',N'-tetraoctyl diglycolamide (TODGA): a thermodynamic study. Radiochim. Acta 2006, 94, 307-312.

(52) Nitsch, W.; Kruis, B. The influence of flow and concentration on the mass transfer mechanism in chelating liquid/liquid-extractions. J. Inorg. Nucl. Chem. 1978, 40,857 $-864$. 
(53) Nave, S.; Modolo, G.; Madic, C.; Testard, F. Aggregation properties of N,N,N',N'tetraoctyl-3-oxapentanediamide (TODGA) in n-dodecane. Solvent Extr. Ion Exch. 2004, 22, 527-551.

(54) Hlushak, S.; Simonin, J.; Caniffi, B.; Moisy, P.; Sorel, C.; Bernard, O. Description of partition equilibria for uranyl nitrate, nitric acid and water extracted by tributyl phosphate in dodecane. Hydrometallurgy 2011, 109, 97 - 105.

(55) Carrott, M.; Bell, K.; Brown, J.; Geist, A.; Gregson, C.; Hères, X.; Maher, C.; Malmbeck, R.; Mason, C.; Modolo, G., et al. Development of a new flowsheet for co-separating the transuranic actinides: the "EURO-GANEX" process. Solvent Extr. Ion Exch. 2014, 32, 447-467.

(56) Ruff, C. M.; Müllich, U.; Geist, A.; Panak, P. J. Complexation of Cm(III) and Eu(III) with a hydrophilic 2,6-bis(1,2,4-triazin-3-yl)-pyridine studied by time-resolved laser fluorescence spectroscopy. Dalton Trans. 2012, 41, 14594-14602.

(57) Finston, H.; Inoue, Y. The effect of $\mathrm{SCN}^{-}$on the extraction of Fe(III)-TTA. J. Inorg. Nucl. Chem. 1967, 29, $199-208$.

(58) Wasan, D. T.; Gu, Z. M.; Li, N. N. Separation of metal ions by ligand-accelerated transfer through liquid surfactant membranes. Faraday Discuss. Chem. Soc. 1984, 77, 67-74.

(59) Simonin, J.-P.; Hendrawan, H.; Dardoize, F.; Clodic, G. Study of salt effects on the kinetics of extraction of cobalt(II) and zinc(II) at trace level by D2EHPA in n-dodecane. Hydrometallurgy 2003, 69, 23 - 38.

(60) Rode, J. E.; Narbutt, J.; Dudek, M. K.; Kazmierski, S.; Dobrowolski, J. C. On the conformation of the actinide-selective hydrophilic $\mathrm{SO}_{3}-\mathrm{Ph}-\mathrm{BTP}$ ligand in aqueous solution. A computational study. J. Mol. Liq. 2016, 219, $224-231$. 
(61) Steczek, Ł.; Rejnis, M.; Narbutt, J.; Charbonnel, M.-C.; Moisy, P. On the stoichiometry and stability of americium(III) complexes with a hydrophilic $\mathrm{SO}_{3}-\mathrm{Ph}-\mathrm{BTP}$ ligand, studied by liquid-liquid extraction. J. Radioanal. Nucl. Chem. 2016, 309, 891-897.

(62) Steczek, L.; Narbutt, J.; Charbonnel, M.-C.; Moisy, P. Determination of formation constants of uranyl(VI) complexes with a hydrophilic SO3-Ph-BTP ligand, using liquidliquid extraction. Nukleonika 2015, 60, 821-827.

(63) Wu, F.; Lv, H.; He, X.; Cheng, Z.; Jia, H.; Xie, S.; Liu, Y.; Ye, G.; He, H. Selective Am(III) stripping with water-soluble PyTri-Diol in nitric acid from HDEHP organic phase. J. Radioanal. Nucl. Chem. 2020, 323, 283-289.

(64) Wilden, A.; Modolo, G.; Schreinemachers, C.; Sadowski, F.; Lange, S.; Sypula, M.; Magnusson, D.; Geist, A.; Lewis, F. W.; Harwood, L. M.; Hudson, M. J. Direct Selective Extraction of Actinides(III) from PUREX Raffinate using a Mixture of $\mathrm{CyMe}_{4} \mathrm{BTBP}$ and TODGA as 1-cycle SANEX Solvent, Part III: Demonstration of a LaboratoryScale Counter-Current Centrifugal Contactor Process. Solvent Extr. Ion Exch. 2013, 31, 519-537.

(65) Modolo, G.; Wilden, A.; Daniels, H.; Geist, A.; Magnusson, D.; Malmbeck, R. Development and demonstration of a new SANEX Partitioning Process for selective actinide(III)/lanthanide(III) separation using a mixture of $\mathrm{CyMe}_{4} \mathrm{BTBP}$ and TODGA. Radiochim. Acta 2013, 101, 155-162. 
9 Abstract Graphic For Table of Contents Only

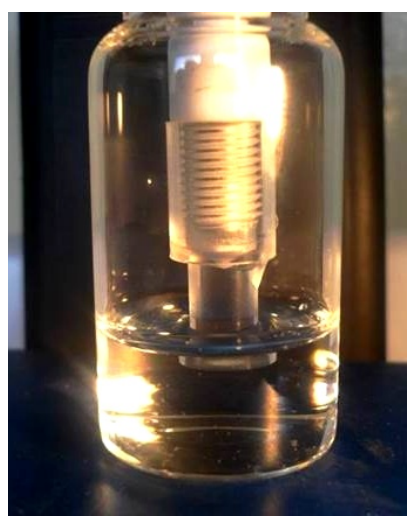

Nitric acid

\section{$\mathrm{Eu}(\mathrm{III}) \mathrm{Am}(\mathrm{III})$}

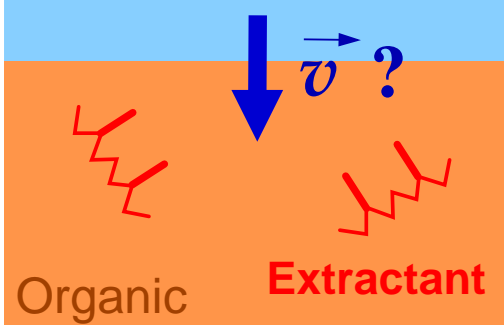

